\title{
Anti-Trypanosoma Activity and Synergistic Effects of Natural and Semi-Synthetic Triterpenes and Predominant Cell Death through Autophagy in Amastigote Forms
}

\author{
Gleison D. P. Bossolani, ${ }^{a}$ Tânia Ueda-Nakamura, ${ }^{a}$ Sueli O. Silva, ${ }^{a}$ Benedito P. Dias Filho, ${ }^{a}$ \\ Tulio O. G. Costa, ${ }^{b}$ Raúl H. R. Quintanilla, ${ }^{c}$ Sabrina T. Martinez, ${ }^{c}$ Valdir F. Veiga-Junior, ${ }^{b, d}$ \\ Angelo C. Pinto ${ }^{\dagger, c, d}$ and Celso V. Nakamura ${ }^{*, a}$ \\ ${ }^{a}$ Departamento de Ciências Básicas da Saúde, Universidade Estadual de Maringá (UEM), \\ Av. Colombo, 5790, 87020-900 Maringá-PR, Brazil \\ ${ }^{b}$ Departamento de Química, Instituto de Ciências Exatas, Universidade Federal do Amazonas (UFAM), \\ Av. Rodrigo Octávio, 6200, 69077-000 Manaus-AM, Brazil
}

'Departamento de Química Orgânica, Instituto de Química, Universidade Federal do Rio de Janeiro (UFRJ), Av. Athos da Silveira Ramos, 149, 21941-909 Rio de Janeiro-RJ, Brazil

${ }^{d}$ Instituto Militar de Engenharia (IME), 22290-270 Rio de Janeiro-RJ, Brazil

\begin{abstract}
Chagas' disease is a parasitic disease with unsatisfactory treatment, mainly in chronic stage. This study aimed to evaluate the trypanocidal activity and action mechanisms of $\alpha / \beta$-amyrin and its semisynthetic derivatives, together with four isolated natural triterpenes, tested against trypomastigote and amastigote forms. The structure-activity relationship was suggested and cytotoxicity was measured. In general, greater polar compounds may have improved the selectivity to the protozoan. Action mechanisms were only performed for the amastigotes of Trypanosoma cruzi by evaluating the ultrastructural alterations, membrane permeability, mitochondrial membrane potential and cell volume, since the majority of compounds displayed promising antiamastigote activities. Triterpenes promoted changes on mitochondrial membrane potential and ultrastructural features that suggest autophagy processes. Both combinations between $\alpha / \beta$-amyrin and 3 - $O$-acetyl-11-oxo- $\alpha / \beta$-amyrin and 3- $O$-acetyl- $\alpha / \beta$-amyrin with benznidazole displayed synergistic effects against amastigotes and antagonistic effects on $\mathrm{LLCMK}_{2}$ cells. The antiamastigote activities, chemical derivatization, drug combinations and action mechanisms revealed to be crucial approaches toward this chronic disease.
\end{abstract}

Keywords: triterpenes, Trypanosoma cruzi, synergistic effects, amastigote, autophagy

\section{Introduction}

Chagas' disease, caused by the flagellate protozoan Trypanosoma cruzi, is a chronic systemic parasitosis that affects about 8 million people worldwide, mostly in Latin America where it is considered endemic. ${ }^{1}$ Symptomatic Chagas' disease is mainly associated with cardiac and enteric consequences that may lead to increased rates of morbidity and mortality. ${ }^{2}$ Unfortunately, there is no satisfactory treatment for the chronic stage of the disease and new anti-T. cruzi drug candidates are needed. The current available drug therapy for Chagas' disease relies on two nitro derivatives: benznidazole and nifurtimox. Both are

\footnotetext{
*e-mail: cvnakamura@uem.br
}

$\dagger$ In memoriam far from the ideal due to their several side effects, the limited efficacy against the genetically heterogeneous parasite, the long-term therapy, and the well-known poor activity in the late chronic phase. ${ }^{2,3}$ In addition, low investments toward drug discovery research for Chagas' disease contribute to the slow advancements in the development of new drugs. ${ }^{4,5}$

Several studies have been conducted to find novel active compounds against $T$. cruzi. The search of natural products is promising source for the discovery of novel drugs, mainly for the neglected diseases. Another approach is that plant-derivative synthetic compounds may have an increased antiparasitic activity and a reduced toxicity through the modifications in their original chemical structure. ${ }^{6,7}$ Triterpenes are widely distributed in nature and isolated from a variety of plant sources, and more than 20,000 triterpenes have been isolated and identified 
from nature. ${ }^{8}$ These compounds have shown a wide spectrum of pharmacologic activities, such as antibacterial, antiviral, antifungal, anti-oxidative, anti-inflammatory, anti-ulcer, anti-hyperlipidemic, hepatoprotective, as well as anti-cancer. ${ }^{9,10}$

Studies with terpenes revealed promising antileishmanial and trypanocidal activities that leads to different types of cellular death mechanisms induced by these compounds. Furthermore, different classes of terpenes have been demonstrated desirable synergistic effects when combined, since drug combination may improve the parasitic activity with lower dosage of these substances, in addition to reducing their undesirable toxic effects. ${ }^{11-17}$ The search for synergic compounds can improve the efficiency of the treatment, reduce their toxicities on mammalian cells and diminish the selection of resistant mutations. . $218-20^{2}$ Alternative strategies have been designed to identify candidates among the already available drugs in the market that could be used in combination to provide synergic effects and improve the chemotherapy efficacy. Antifungal agents, tricyclic antidepressants and several antipsychotics have been studied in combination with benznidazole in order to search new combination therapy approaches. ${ }^{19-21}$

After the discovery of several biological activities of ursolic acid and their derivatives, the search for sustainable sources of triterpenes with promising biological activities has increased in order to improve their original biological activities. Amyrins, hydroxylated monounsaturated alcohols obtained from several triterpenic skeletons, mainly from ursane and oleanane, are commonly observed in apolar extracts of plants and abundantly available in oil resins that is produced by Burseraceae species, well-known incense, frankincense or breu. ${ }^{22-25}$

This study evaluated the antiprotozoal activities of twelve triterpenoid and combinatorial effects, as well as the cytotoxicity against mammalian cells. The structure-activity relationship (SAR) between the chemical structure and biological properties of the compounds was also suggested. Ultrastructural changes, integrity of the mitochondria and cellular membrane and cell volume were also studied to investigate some action mechanisms of the triterpenes.

\section{Experimental}

\section{Syntheses}

\section{$\alpha / \beta$-Amyrin (1)}

The binary mixture of triterpenoids $\alpha / \beta$-amyrin was isolated from Protium resin. ${ }^{26}$ The high purity of this mixture was considered based on the only two peaks in the analyses of gas chromatography (GC) and high performance liquid chromatography (HPLC). These two analyses, performed and published previously, were used to define, together with proton nuclear magnetic resonance ( ${ }^{1} \mathrm{H} \mathrm{NMR}$ ), the amount of these $\alpha$ - and $\beta$-amyrins in this mixture was 66 and 34\%, respectively.

\section{3-O-Fumaryl- $\alpha / \beta$-amyrin (2)}

A solution of $\alpha / \beta$-amyrin $(0.30 \mathrm{~g}, 0.703 \mathrm{mmol})$ in diclorometane $\left(\mathrm{CH}_{2} \mathrm{Cl}_{2}\right)$, maleic anhydride $(0.55 \mathrm{~g}$, $5.6 \mathrm{mmol}$ ) and 4-dimethylaminopyridine (DMAP, $0.02 \mathrm{~g}$, $0.164 \mathrm{mmol}$ ) was refluxed for $24 \mathrm{~h}$. Then, the mixture was concentrated and subjected to liquid-liquid extraction. Column chromatography (silica gel 60, Merck, hexane:ethyl acetate, 95:5) of the crude residue was performed to give expected pure compound $(0.33 \mathrm{~g}, 0.629 \mathrm{mmol})$, with yield of $89 \%$, and appearance light yellow; IR $(\mathrm{KBr}) v / \mathrm{cm}^{-1}$ $3126(\mathrm{O}-\mathrm{H}), 1738(\mathrm{C}=\mathrm{O}$, ester $), 1686(\mathrm{C}=\mathrm{O}$, acid $)$, $1308\left(\mathrm{C}(=\mathrm{O})-\mathrm{O}\right.$, ester); ${ }^{13} \mathrm{C}$ NMR $\left(75 \mathrm{MHz}, \mathrm{CDCl}_{3}\right.$ ) was compared with literature data, ${ }^{27} \delta_{\mathrm{C}}(\mathrm{ppm}), \alpha$ isomer, $\delta 15.6$ (C-25), 15.6 (C-24), 16.8 (C-26), 18.2 (C-6), 23.5 (C-11), 23.7 (C-30), 26 (C-27), 26.1 (C-15), 26.9 (C-2), 26.9 (C-16), 28.1 (C-23), 28.4 (C-28), 31.1 (C-20), 32.5 (C-7), 32.5 (C-17), 33.3 (C-29), 34.7 (C-21), 36.8 (C-10), 37.1 (C-22), 38.1 (C-1), 39.8 (C-8), 39.8 (C-4), 41.7 (C-14), 46.7 (C-19), 47.2 (C-18), 47.5 (C-9), 55.2 (C-5), 85.1 (C-3), 121.4 (C-12), 129.1 (C'2), 137.8 (C'3), 145.3 (C-13), 164.1 (C'4), 168 (C'1); $\beta$ isomer, 15.7 (C-24), 15.7 (C-25), 16.8 (C-26), 17.5 (C-29), 18.2 (C-6), 21.4 (C-30), 23.2 (C-27), 23.3 (C-11), 26.6 (C-16), 26.6 (C-15), 28.1 (C-2), 28.1 (C-28), 28.7 (C-23), 31.2 (C-21), 32.8 (C-7), 33.8 (C-17), 36.8 (C-10), 38.3 (C-1), 38.3 (C-4), 39.6 (C-19), 39.6 (C-20), 40 (C-8), 41.5 (C-22), 42.1 (C-14), 47.6 (C-9), 55.2 (C-5), 59 (C-18), 85.1 (C-3), 124.1 (C-12), 139.7 (C-13); HRMS (ESI) $m / z$ [M - H] $]^{-}$observed 523.3791; $\mathrm{C}_{34} \mathrm{H}_{51} \mathrm{O}_{4}$ requires 523.3787 .

\section{3-O-Succinyl- $\alpha / \beta$-amyrin (3)}

To obtain a solution of 3-O-succinyl- $\alpha / \beta$-amyrin (3), succinic anhydride $(0.56 \mathrm{~g}, 5.6 \mathrm{mmol})$ and DMAP $(0.02 \mathrm{~g}, 0.164 \mathrm{mmol})$ were added in $\alpha / \beta$-amyrin $(0.30 \mathrm{~g}$, $0.703 \mathrm{mmol}$ ) in $\mathrm{CH}_{2} \mathrm{Cl}_{2}$, and refluxed for $24 \mathrm{~h}$. Then, the mixture was concentrated and subjected to liquidliquid extraction. It was obtained a white solid $(0.35 \mathrm{~g}$, $0.664 \mathrm{mmol})$ with yield of $94 \%$; IR (KBr) $v / \mathrm{cm}^{-1} 3443$ $(\mathrm{O}-\mathrm{H}), 1732(\mathrm{C}=\mathrm{O}$, ester $), 1713(\mathrm{C}=\mathrm{O}$, acid $), 1308$ $\left(\mathrm{C}(=\mathrm{O})-\mathrm{O}\right.$, ester); ${ }^{13} \mathrm{C}$ NMR $\left(75 \mathrm{MHz}, \mathrm{CDCl}_{3}\right)$ was compared with literature data, ${ }^{27} \delta_{\mathrm{C}}(\mathrm{ppm}), \alpha$ isomer, $\delta 15.7$ (C-24), 15.7 (C-25), 16.8 (C-26), 17.5 (C-29), 18.2 (C-6), 21.4 (C-30), 23.2 (C-27), 23.5 (C-11), 26.6 (C-15), 26.6 (C-16), 28 (C-23), 28 (C-28), 28.7 (C-2), 29.3 (C'2), 29.3 (C’3), 31.2 (C-21), 32.8 (C-7), 33.7 (C-17), 36.7 (C-10), 
38.4 (C-1), 39.6 (C-4), 39.6 (C-19), 39.6 (C-20), 40 (C-8), 41.5 (C-22), 42 (C-14), 47.6 (C-9), 55.2 (C-5), 59 (C-18), 81.6 (C-3), 124.3 (C-12), 139.6 (C-13), 171.9 (C'1), 177.2 (C'4); $\beta$ isomer, 15.5 (C-24), 15.5 (C-25), 16.8 (C-26), 18.2 (C-6), 23.5 (C-11), 23.7 (C-30), 26 (C-16), 26 (C-27), 26.1 (C-15), 26.9 (C-2), 27.9 (C-23), 28.4 (C-28), 29.4 (C'2), 29.4 (C’3), 31.1 (C-20), 32.5 (C-7), 32.5 (C-17), 33.3 (C-29), 34.7 (C-21), 36.8 (C-10), 37.1 (C-22), 38.2 (C-1), 39.8 (C-4), 39.8 (C-8), 41.7 (C-14), 46.8 (C-19), 47.2 (C-18), 47.5 (C-9), 55.2 (C-5), 81.5 (C-3), 121.6 (C-12), 145.2 (C-13), 171.9 (C'1), 177.1 (C'4); HRMS (ESI) $\mathrm{m} / \mathrm{z}$ $[\mathrm{M}-\mathrm{H}]^{-}$observed 525.3969; $\mathrm{C}_{34} \mathrm{H}_{53} \mathrm{O}_{4}$ requires 525.3949.

\section{3-O-Acetyl- $\alpha / \beta$-amyrin (4)}

A solution of $\alpha / \beta$-amyrin $(0.5 \mathrm{~g}, 1.17 \mathrm{mmol})$, acetic anhydride $(3.0 \mathrm{~mL})$ and DMAP $(0.01 \mathrm{~g}, 0.082 \mathrm{mmol})$ was refluxed for $30 \mathrm{~min}$. Then, the mixture was concentrated and subjected to liquid-liquid extraction with $\mathrm{CH}_{2} \mathrm{Cl}_{2}$ in water $\left(\mathrm{CH}_{2} \mathrm{Cl}_{2} / \mathrm{H}_{2} \mathrm{O}\right)$. This derivate binary mixture was obtained as a white solid $(0.54 \mathrm{~g}, 1.15 \mathrm{mmol})$ with yield of $98 \%$; $\mathrm{IR}(\mathrm{KBr}) v / \mathrm{cm}^{-1} 1736(\mathrm{C}=\mathrm{O}$, ester $), 1243(\mathrm{C}(=\mathrm{O})-\mathrm{O}$, ester $)$; ${ }^{13} \mathrm{C} \mathrm{NMR}\left(75 \mathrm{MHz}, \mathrm{CDCl}_{3}\right.$ ) was compared with literature data, ${ }^{28,29} \delta_{\mathrm{C}}(\mathrm{ppm}), \alpha$ isomer, $\delta 15(\mathrm{C}-25), 16.6(\mathrm{C}-26)$, 16.8 (C-24), 17.4 (C-29), 18.2 (C-6), 21.3 (C-30), 23.1 (C-11), 23.4 (C-27), 25.9 (C-2), 26.6 (C-16), 28.1 (C-28), 28.2 (C-23), 28.7 (C-15), 31.3 (C-21), 32.8 (C-7), 33.7 (C-17), 36.7 (C-10), 37.7 (C-4), 38.5 (C-1), 39.6 (C-19), 39.6 (C-20), 40 (C-8), 41.5 (C-22), 42 (C-14), 47.7 (C-9), 55.2 (C-5), 59 (C-18), 80.9 (C-3), 124.3 (C-12), 139.6 (C-13); $\beta$ isomer, 15.7 (C-25), 16.8 (C-24), 16.8 (C-26), 18.2 (C-6), 21.3 (C'2), 23.4 (C-11), 23.6 (C-2), 26.1 (C-27), 26.2 (C-16), 26.6 (C-30), 26.9 (C-28), 28.1 (C-23), 28.4 (C-15), 31 (C-20), 32.5 (C-17), 32.6 (C-7), 33.4 (C-29), 34.8 (C-21), 36.8 (C-10), 37.1 (C-22), 37.7 (C-4), 38.2 (C-1), 39.6 (C-8), 41.5 (C-14), 46.8 (C-19), 47.2 (C-18), 47.5 (C-9), 55.3 (C-5), 80.7 (C-3), 121.6 (C-12), 145.2 (C-13), 170.9 (C'1); GC-MS (EI), m/z $468\left[\right.$ [M] $^{+}$(4), 218 (100), 203 (22-50).

\section{3-O-Phthaloyl- $\alpha / \beta$-amyrin (5)}

A solution of $\alpha / \beta$-amyrin $(0.30 \mathrm{~g}, 0.703 \mathrm{mmol})$ in $\mathrm{CH}_{2} \mathrm{Cl}_{2}$, phthalic anhydride $(0.83 \mathrm{~g}, 5.6 \mathrm{mmol})$ and DMAP $(0.02 \mathrm{~g}, 0.164 \mathrm{mmol})$ was refluxed for $24 \mathrm{~h}$. Then, the mixture was concentrated and subjected to liquid-liquid extraction on $\mathrm{CH}_{2} \mathrm{Cl}_{2} / \mathrm{H}_{2} \mathrm{O}$. Column chromatography (silica gel 60, Merck, hexane:ethyl acetate, 95:5) of the crude organic residue was performed to give a white solid $(0.37 \mathrm{~g}, 0.644 \mathrm{mmol})$, with yield of $92 \%$; IR $(\mathrm{KBr}) v / \mathrm{cm}^{-1}$ $3460(\mathrm{O}-\mathrm{H}), 1713(\mathrm{C}=\mathrm{O}$, ester $), 1641(\mathrm{C}=\mathrm{O}$, acid $), 1300$ $(\mathrm{C}(=\mathrm{O})-\mathrm{O}$, ester $) ;{ }^{13} \mathrm{C}$ NMR $\left(75 \mathrm{MHz}, \mathrm{CDCl}_{3}\right)$ was compared with literature data, ${ }^{27} \delta_{\mathrm{C}}(\mathrm{ppm}), \alpha$ isomer, $\delta 15.7$
(C-25), 16.6 (C-26), 16.8 (C-24), 17.5 (C-29), 18.2 (C-6), 21.4 (C-30), 23.2 (C-11), 23.4 (C-27), 26.6 (C-16), 28.1 (C-2), 28.1 (C-28), 28.2 (C-23), 28.7 (C-15), 31.3 (C-21), 32.8 (C-7), 33.7 (C-17), 36.7 (C-10), 38.4 (C-1), 39.6 (C-4), 39.6 (C-19), 39.6 (C-20), 40 (C-8), 41.5 (C-22), 42 (C-14), 47.6 (C-9), 55.3 (C-5), 59 (C-18), 83.1 (C-3), 124.3 (C-12), 129 (C'3), 129.9 (C'6), 131.1 (C'2), 131.4 (C'7), 132.7 (C'4), 133.4 (C'5), 139.6 (C-13), 168 (C'1), 171.4 (C'8); $\beta$ isomer, 15.7 (C-25), 16.8 (C-24), 16.8 (C-26), 18.2 (C-6), 23.6 (C-30), 23.7 (C-11), 25.9 (C-27), 26.2 (C-16), 28.1 (C-23), 28.4 (C-15), 28.4 (C-28), 28.6 (C-2), 31 (C-20), 31.1 (C-21), 32.7 (C-17), 32.8 (C-7), 33.4 (C-29), 36.8 (C-10), 37.1 (C-22), 38.5 (C-1), 39.6 (C-4), 39.6 (C-8), 41.7 (C-14), 46.8 (C-19), 47.5 (C-9), 47.6 (C-18), 55.4 (C-5), 83.1 (C-3), 121.6 (C-12), 129 (C'3), 129.9 (C'6), 131.1 (C'2), 131.4 (C'7), 132.7 (C'4), 133.4 (C'5), 145.2 (C-13), 168 (C'1), 171.4 (C'8); HRMS (ESI) $\mathrm{m} / z$ [M - H] ${ }^{-}$ observed 573.3930; $\mathrm{C}_{38} \mathrm{H}_{53} \mathrm{O}_{4}$ requires 573.3943.

\section{3-O-Acetyl-11-oxo- $\alpha / \beta$-amyrin (6)}

To obtain a solution of 3-O-acetyl-11-oxo$\alpha / \beta$-amyrin (6), acetic anhydride $(3 \mathrm{~mL})$, acetic acid and tert-butyl chromate $(3 \mathrm{~mL})$ were added in the solution of 3 - $O$-acetyl- $\alpha / \beta$-amyrin $(0.20 \mathrm{~g}, 0.427 \mathrm{mmol})$, and refluxed for $6 \mathrm{~h}$. Then, the mixture was concentrated and subjected to liquid-liquid extraction with $\mathrm{CH}_{2} \mathrm{Cl}_{2} / \mathrm{H}_{2} \mathrm{O}$ and oxalic acid (5\%). The oxidation yield was $97 \% ;{ }^{13} \mathrm{C}$ NMR $(75 \mathrm{MHz}$, $\mathrm{CDCl}_{3}$ ) was compared with literature data, ${ }^{29,30} \delta_{\mathrm{C}}(\mathrm{ppm})$, $\alpha$ isomer, $\delta 16.5$ (C-25), 16.7 (C-24), 17.4 (C-26), 17.4 (C-29), 18.5 (C-6), 21.1 (C-30), 21.2 (C’2), 23.5 (C-2), 23.6 (C-27), 27.2 (C-16), 27.4 (C-15), 28 (C-23), 28.8 (C-28), 30.9 (C-21), 32.8 (C-7), 33.9 (C-17), 36.8 (C-10), 38 (C-4), 38.8 (C-1), 39.2 (C-19), 39.3 (C-20), 40.9 (C-8), 43.6 (C-22), 45.1 (C-14), 55 (C-9), 59 (C-5), 61.4 (C-18), 80.6 (C-3), 130.4 (C-12), 165 (C-13), 171 (C'1), 199.6 (C-11); $\beta$ isomer, 16.4 (C-25), 16.6 (C-24), 17.4 (C-26), 18.6 (C-6), 23.4 (C-2), 23.5 (C-27), 23.5 (C-30), 26.4 (C-15), 26.4 (C-16), 28 (C-23), 28.7 (C-28), 31 (C-20), 32.3 (C-17), 32.6 (C-7), 33 (C-29), 34.4 (C-21), 36.5 (C-22), 36.9 (C-10), 38 (C-4), 38.7 (C-1), 43.3 (C-8), 45 (C-19), 45.4 (C-14), 47.5 (C-18), 55 (C-5), 61.5 (C-9), 80.6 (C-3), 128 (C-12), 170.6 (C-13), 200.1 (C-11); GC-MS (EI), $\mathrm{m} / \mathrm{z}$ $482[\mathrm{M}]^{+}(4), 232$ (60-100), 273 (80-100).

\section{3-O-Succinyl-11-oxo- $\alpha / \beta$-amyrin (7)}

A solution of $3-O$-succinyl- $\alpha / \beta$-amyrin $(0.20 \mathrm{~g}$, $0.380 \mathrm{mmol})$, acetic anhydride $(3 \mathrm{~mL})$ and acetic acid tert-butyl chromate $(3 \mathrm{~mL})$ was refluxed for $6 \mathrm{~h}$. The mixture was concentrated and subjected to liquid-liquid extraction with $\mathrm{CH}_{2} \mathrm{Cl}_{2} / \mathrm{H}_{2} \mathrm{O}$ and oxalic acid (5\%). The oxidation yield was $97 \%$; ${ }^{13} \mathrm{C}$ NMR (75 MHz, $\mathrm{CDCl}_{3}$ ) was compared with 
literature data, ${ }^{27,30} \delta_{\mathrm{C}}(\mathrm{ppm}), \alpha$ isomer, $\delta 16.5(\mathrm{C}-25), 16.7$ (C-24), 17.4 (C-26), 17.4 (C-29), 18.5 (C-6), 21.1 (C-30), 23.4 (C-27), 27.2 (C-16), 27.4 (C-15), 28 (C-23), 28 (C-28), 28.8 (C-2), 29 (C'3), 29.3 (C'2), 31 (C-21), 32.4 (C-7), 33.9 (C-17), 36.8 (C-10), 38.1 (C-4), 38.8 (C-1), 39.2 (C-19), 39.3 (C-20), 40.9 (C-8), 43.6 (C-22), 45.1 (C-14), 55 (C-9), 59 (C-5), 61.4 (C-18), 81.2 (C-3), 130.3 (C-12), 165.1 (C-13), 171.8 (C'4), 177.5 (C'1), 199.7 (C-11); $\beta$ isomer, 16.4 (C-25), 16.6 (C-24), 17.4 (C-26), 18.6 (C-6), 23.4 (C-2), 23.5 (C-27), 23.5 (C-30), 26.4 (C-15), 26.4 (C-16), 28 (C-23), 28.7 (C-28), 29 (C'3), 29.3 (C'2), 30.9 (C-20), 32.3 (C-17), 32.8 (C-7), 33.2 (C-29), 34.4 (C-21), 36.5 (C-22), 36.9 (C-10), 38 (C-4), 38.7 (C-1), 43.3 (C-8), 45.1 (C-19), 45.4 (C-14), 47.6 (C-18), 55 (C-5), 61.5 (C-9), 81.2 (C-3), 128 (C-12), 170.8 (C-13), 171.8 (C'1), 177.5 (C'4), 200.2 (C-11); HRMS (ESI) $\mathrm{m} / \mathrm{z}$ [M - H] $]^{-}$observed 539.3714; $\mathrm{C}_{34} \mathrm{H}_{51} \mathrm{O}_{5}$ requires 539.3742

\section{3-O-Phthaloyl-11-oxo- $\alpha / \beta$-amyrin (8)}

To obtain the solution of 3-O-phthaloyl-11-oxo$\alpha / \beta$-amyrin $(8)$, acetic anhydride $(3 \mathrm{~mL})$ and acetic acid tert-butyl chromate $(3 \mathrm{~mL})$ were added in the 3- $O$-phthaloyl- $\alpha / \beta$-amyrin $(0.20 \mathrm{~g}, 0.348 \mathrm{mmol})$, and refluxed for $6 \mathrm{~h}$. Then, the mixture was concentrated and subjected to liquid-liquid extraction with $\mathrm{CH}_{2} \mathrm{Cl}_{2} / \mathrm{H}_{2} \mathrm{O}$ and oxalic acid (5\%). The oxidation yield was $97 \% ;{ }^{13} \mathrm{C}$ NMR $\left(75 \mathrm{MHz}, \mathrm{CDCl}_{3}\right.$ ) was compared with literature data, ${ }^{27,30}$ $\delta_{\mathrm{C}}(\mathrm{ppm}), \alpha$ isomer, $\delta 16.5(\mathrm{C}-25), 16.8(\mathrm{C}-24), 17.5$ (C-26), 17.5 (C-29), 18.5 (C-6), 21.1 (C-30), 23 (C-27), 27.2 (C-16), 27.4 (C-15), 28.1 (C-23), 28.1 (C-28), 28.8 (C-2), 32.8 (C-7), 33.9 (C-17), 33.9 (C-21), 36.9 (C-10), 38.4 (C-1), 39.2 (C-20), 39.3 (C-19), 40.9 (C-4), 40.9 (C-8), 43.8 (C-22), 45.2 (C-14), 55.2 (C-9), 59 (C-5), 61.4 (C-18), 82.8 (C-3), 128.9 (C'3), 129.9 (C'6), 130.3 (C-12), 130.8 (C'2), 131.7 (C'7), 133.3 (C'4), 133.3 (C'5), 165.4 (C-13), 171.3 (C'1), 171.3 (C'8), 199.9 (C-11); $\beta$ isomer, 16.4 (C-25), 16.8 (C-24), 17.5 (C-26), 18.6 (C-6), 23.4 (C-27), 23.4 (C-30), 26.1 (C-16), 26.4 (C-15), 28.1 (C-23), 28.1 (C-28), 28.8 (C-2), 31 (C-20), 32.6 (C-7), 33.8 (C-29), 33.9 (C-17), 33.9 (C-21), 36.9 (C-10), 38.4 (C-1), 40.9 (C-4), 40.9 (C-22), 43.6 (C-8), 45.2 (C-19), 45.4 (C-14), 55.2 (C-5), 59 (C-18), 61.6 (C-9), 82.8 (C-3), 128.9 (C-12), 128.9 (C'3), 129.9 (C'6), 130.8 (C'2), 131.7 (C'7), 133.3 (C'4), 133.3 (C'5), 171.3 (C-13), 171.3 (C'1), 171.3 (C'8), 200.4 (C-11); HRMS (ESI) $\mathrm{m} / \mathrm{z}[\mathrm{M}-\mathrm{H}]^{-}$observed 587.3708; $\mathrm{C}_{38} \mathrm{H}_{51} \mathrm{O}_{5}$ requires 587.3742.

\section{Lup-20(29)-ene-3 $\beta, 6 \beta, 16 \beta$-triol (9)}

This natural compound was previously isolated and characterized by our collaborator ${ }^{31}$ from Combretum leprosum and provided a sample to this study.

\section{Lup-20(29)-en-3-one (10)}

For a solution of Protium resin $^{26}(0.100 \mathrm{~g})$ in acetone $(10 \mathrm{~mL})$, Jones reagent was slowly added until green-blue color. Then, isopropanol $(2 \mathrm{~mL})$ was added and, after $10 \mathrm{~min}$, the product was washed with aqueous solution of oxalic acid $(10 \%, 3 \times 10 \mathrm{~mL})$ and water $(3 \times 10 \mathrm{~mL})$, dried with sodium sulfate $\left(\mathrm{Na}_{2} \mathrm{SO}_{4}\right)$ and the solvent evaporated, under vacuum. The product $(85 \mathrm{mg})$ was subjected to separation by semi-preparative HPLC, thus obtaining a white solid $(10 \mathrm{mg})$, which was characterized as lup-20(29)-en-3-one; ${ }^{13} \mathrm{C} \mathrm{NMR} \mathrm{(100} \mathrm{MHz,} \mathrm{CDCl}_{3}$ ) was compared with literature data. ${ }^{32,33} \delta 14.6$ (C-27), 15.9 (C-26), 16.1 (C-25), 18.2 (C-28), 19.4 (C-30), 19.8 (C-6), 21.2 (C-24), 21.58 (C-11), 25.23 (C-12), 26.8 (C-23), 27.5 (C-15), 29.9 (C-21), 33.7 (C-7), 34.3 (C-2), 35.6 (C-16), 37 (C-10), 38.3 (C-13), 39.7 (C-1), 40.1 (C-22), 40.9 (C-8), 43 (C-17), 43.1 (C-14), 47.5 (C-4), 48.1 (C-19), 48.3 (C-18), 49.9 (C-9), 55 (C-5), 109.5 (C-29), 151 (C-20), 218.5 (C-3); GC-MS (EI) $\mathrm{C}_{30} \mathrm{H}_{48} \mathrm{O} \mathrm{m} / \mathrm{z}$ (\%) 424 (32) [M] $]^{+*}, 409$ (20), 313 (27), 245 (25), 218 (34), 205 (100), 189 (40), 109 (94), 95 (80), 81 (60).

\section{Betulinic acid (11)}

This natural compound was previously isolated and characterized by our collaborator from Gustavia augusta L. (Lecythidaceae family) and provided a sample to this study. ${ }^{34}$

\section{Lanosta-8,24-dien-3-one (12)}

Lanosta-8,24-dien-3-ol (50-60\%) was purchased from Sigma and purified as in Kavtaradze et al. ${ }^{35}$ Subsequently, the lanosta-8,24-dien-3-ol was oxidized with the Jones reagent in order to obtain the lup-20(29)-en-3-one. ${ }^{13} \mathrm{C} \mathrm{NMR}\left(100 \mathrm{MHz}, \mathrm{CDCl}_{3}\right)$ was compared with literature data. ${ }^{36,37} \delta 15.8$ (C-18), 17.8 (C-26), 19 (C-21), 19.9 (C-6), 20.4 (C-19), 21.2 (C-29), 21.5 (C-11), 24.4 (C-30), 24.9 (C-23), 25.9 (C-27), 26.8 (C-28), 27.6 (C-7), 28.3 (C-16), 29.8 (C-15), 30.9 (C-12), 34.7 (C-2), 35.5 (C-1), 35.7 (C-20), 36 (C-22), 37.2 (C-10), 44.2 (C-13), 47.4 (C-4), 49.8 (C-14), 50.2 (C-17), 51.6 (C-5), 125.3 (C-24), 131.1 (C-25), 132.7 (C-9), 134.8 (C-8), 218.6 (C-3); GC-MS (EI), $m / z(\%) 424(25)[\mathrm{M}]^{+*}, 409$ (100), 257 (55), 245 (25), 109 (39).

\section{Equipments}

Mass spectra were performed in a gas chromatograph, Agilent 6890, equipped with a mass selective detector (MS) (with electron impact ionization, EI, $70 \mathrm{eV}$ ). Samples were injected using split ratio $1 / 10$. The silica capillary column DB-5 (Agilent J\&W, $30 \mathrm{~m} \times 0.25 \mathrm{~mm}$ i.d.) coated 
with $5 \%$ phenylpoly (methylsiloxane) $(0.25 \mu \mathrm{m}$ film thickness) was used. The operating temperatures were as follows: injector, $280^{\circ} \mathrm{C}$; ionization chamber, $230{ }^{\circ} \mathrm{C}$; and transfer line, $280^{\circ} \mathrm{C}$. The carrier gas was helium with flow $1 \mathrm{~mL} \mathrm{~min}{ }^{-1}$. NMR spectra $\left({ }^{1} \mathrm{H}\right.$ and $\left.{ }^{13} \mathrm{C}\right)$ were recorded on a Bruker (300 and $400 \mathrm{MHz}$ for ${ }^{1} \mathrm{H} ; 75$ and $100 \mathrm{MHz}$ for ${ }^{13} \mathrm{C}$ ) spectrometer, and $\mathrm{CDCl}_{3}$ was used as solvent and an internal reference. Analysis by HPLC was performed on an Agilent liquid chromatograph, model HP 1100, equipped with UV detector. Columns used were: Zarbax 300SB-C18 analytical $(4.6 \times 150 \mathrm{~mm}, 5 \mu \mathrm{m})$ and Zorbax 300SB-C18 semi-preparative $(9.4 \times 250 \mathrm{~mm}, 5 \mu \mathrm{m})$. As mobile phase was used acetonitrile and acid water $(\mathrm{pH} \mathrm{4}$, with acetic acid) in the proportions: 88:12, 90:10 and 95:5 (\% v/v), with flow $0.7 \mathrm{~mL} \mathrm{~min}{ }^{-1}$ (analytical) and $3.0 \mathrm{~mL} \mathrm{~min}^{-1}$ (semi-preparative). Analysis was monitored at $200 \mathrm{~nm}$. HRESI-MS analysis was performed on a mass spectrometer Waters MIcromass Q-TOF Micro (Milford, MA, USA), equipped with an ESI. The infrared (IR) spectra were recorded on a Fourier transform infrared spectrophotometer (FTIR) model Magna IR 760.

\section{Activity on trypomastigotes}

In order to obtain tissue culture-derived trypomastigote forms, LLCMK $_{2}$ cells (Macaca mulatta epithelial kidney cells) were cultivated in DMEM (Dulbecco's Modified Eagle Medium, pH 7.4, Gibco Invitrogen Co., Grand Island, NY), diluted in $10 \%$ SFB (bovine fetal serum) in a $5 \% \mathrm{CO}_{2}$ atmosphere at $37{ }^{\circ} \mathrm{C}$. Trypomastigotes were harvested from the supernatant of infected $\mathrm{LLCMK}_{2}$ and added to 96 -well plates at $1 \times 10^{7}$ parasites $\mathrm{mL}^{-1}$ in the presence and absence of increasing concentrations of the triterpenoids up to the maximum concentration of $100 \mu \mathrm{M}$. This assay was incubated at $37{ }^{\circ} \mathrm{C}$ in a $5 \% \mathrm{CO}_{2}$ atmosphere. The trypomastigote motility was determined by using the Pizzi-Brener method. ${ }^{38}$ Briefly, $5 \mu \mathrm{L}$ aliquots from each well were removed and deposited on slides, coverslipped, and analyzed immediately. Motility reflected parasite viability. The concentration that killed $50 \%$ of the parasites $\left(\mathrm{EC}_{50}\right)$ was calculated.

\section{Activity on amastigotes}

In order to evaluate the activity of triterpenoids against the intracellular forms of the parasite, $\mathrm{LLCMK}_{2}$ cells were deposited on glass coverslips in 24-well microplates at a concentration of $2.5 \times 10^{5}$ cells $\mathrm{mL}^{-1}$. After the monolayer formation, the trypomastigote forms (10 trypomastigotes/ 1 LLCMK $_{2}$ ratio) were added to each well, and the plates were incubated for $24 \mathrm{~h}$. After that, the medium that contained the parasites was removed, the cells were washed in phosphate-buffered saline (PBS), and DMEM with or without increasing concentrations of the compounds was added. The cells were maintained for $96 \mathrm{~h}$ at $37{ }^{\circ} \mathrm{C}$ in a $5 \% \mathrm{CO}_{2}$ atmosphere. After the incubation period, the glass coverslips were fixed with methanol and Giemsa staining and permanently mounted with Entellan (Merck, Darmstadt, Germany). Under a light microscope, a total of 200 mammalian cells were counted and the percentage of the infected cells and number of amastigotes per cell were determined. The results were expressed as the survival index. The control infected without treatment was considered as $100 \%$, and the results for the treated-groups were comparatively evaluated, and the concentrations that inhibits $50 \%\left(\mathrm{IC}_{50}\right)$ and $90 \%\left(\mathrm{IC}_{90}\right)$ were determined.

\section{Cytotoxicity assay}

Cytotoxicity was assessed to determinate the cell viability by using a MTT (3-[4,5-dimethylthiazol-2-yl]2,5-diphenyltetrazolium bromide) assay. ${ }^{39}$ This colorimetric assay is based on the ability of the viable mitochondria to convert MTT, a water-soluble tetrazolium salt, into an insoluble purple-colored formazan precipitate. $\mathrm{LLCMK}_{2}$ cell line was plated and incubated for $24 \mathrm{~h}$ at $37{ }^{\circ} \mathrm{C}$ with $5 \% \mathrm{CO}_{2}$. Afterwards, the medium was removed and the cells were treated with different concentrations of the compounds and incubated for $96 \mathrm{~h}$ at $37{ }^{\circ} \mathrm{C}$ with $5 \% \mathrm{CO}_{2}$ atmosphere. The cell wells with fresh medium and $10 \%$ SFB without treatment were included as controls. After $96 \mathrm{~h}$ of incubation, the cells were washed in PBS, and $50 \mu \mathrm{L}$ of MTT ( $2 \mathrm{mg} \mathrm{mL}^{-1}$ ) were added to each well. The formazan crystals were solubilized in DMSO (dimethyl sulfoxide), and the absorbance was read at $570 \mathrm{~nm}$ in a microplate reader (BioTek, Power Wave XS). All the experiments were carried out in duplicate. The means were determined from at least three experiments. The selectivity index (SI) was calculated by $\mathrm{CC}_{50}$ (cytotoxic concentration for $50 \%$ of the cells) of the $\mathrm{LLCMK}_{2}$ divided by $\mathrm{IC}_{50}$ of the amastigote forms of $T$. cruzi.

\section{Haemolytic assay}

The cytotoxicity of the twelve compounds was also evaluated against human red blood cells. Blood (A+ type) from a healthy human donor was collected, defibrinated, and washed in glycosylated saline in order to remove free hemoglobin from the defibrinization process. Red blood cells were added to Eppendorfs with $6 \%$ glycosylated saline with different concentrations of triterpenoids $(50-2000 \mu \mathrm{M})$, and then incubated for $3 \mathrm{~h}$ at $37{ }^{\circ} \mathrm{C}$. The supernatant was transferred to 96 -well plates 
and read at $550 \mathrm{~nm}$ in a microplate reader. To calculate the percentage of hemolysis, $1 \%$ Triton $\mathrm{X}-100$ was used as a positive control.

\section{Drug combination assay}

To verify the combinatory effects between triterpenes and the combination of one of them with benznidazole against the amastigote forms and $\mathrm{LLCMK}_{2}$ cells, three compounds were randomly chosen $(\alpha / \beta$-amyrin, 3- $O$-acetyl$\alpha / \beta$-amyrin and 3- $O$-acetyl-11-oxo- $\alpha / \beta$-amyrin). Two drug interaction assays between triterpenes were performed by using amastigote forms and combinations between $\alpha / \beta$-amyrin with 3-O-acetyl-11-oxo- $\alpha / \beta$-amyrin, in different concentrations. The compound 3-O-acetyl$\alpha / \beta$-amyrin was only combined with benznidazole (2.5-40.0 $\mu \mathrm{M})$ to evaluate the synergy with the standard drug. As described above, the same experimental assay of cytotoxicity against nucleated cells and antiamastigote activity of $T$. cruzi was carried out. The experimental design consists in combinations of at least four concentrations of each drug arranged in a checkerboard at a 1:2 concentration ratio. To evaluate the combinational effect, the combination index (CI) method proposed by Chou and Talalay ${ }^{40}$ was adopted. The data were mathematically calculated with the combination index

$$
\begin{aligned}
\mathrm{CI}= & {\left[\mathrm{IC}_{50 \text { drug A combined }} / \mathrm{IC}_{50 \text { drug A alone }}\right]+} \\
& {\left[\mathrm{IC}_{50 \text { drug B combined }} / \mathrm{IC}_{50 \text { drug B alone }}\right] }
\end{aligned}
$$

(based on the sum of division data of the $\mathrm{IC}_{50}$ of the drug $\mathrm{A}$ combined with $\mathrm{B}$ divided by $\mathrm{IC}_{50}$ of the drug $\mathrm{A}$ when used separately, plus the division data of the $\mathrm{IC}_{50}$ of the drug $\mathrm{B}$ combined with $\mathrm{A}$ by $\mathrm{IC}_{50}$ when used alone) in which $\mathrm{CI}$ values less, equal, and more than 1 indicate combinatorial effects of synergism, additive, and antagonism, respectively. The data were also graphically expressed in an isobologram.

\section{Transmission electron microscopy (TEM)}

To evaluate the effect of the compounds on the morphology of intracellular amastigote forms by TEM, the compounds 3-O-phthaloyl- $\alpha / \beta$-amyrin, 3-O-succinyl11 -oxo- $\alpha / \beta$-amyrin and lup-20(29)-en-3-one, as well as the compounds $\alpha / \beta$-amyrin and 3- $O$-acetyl-11-oxo- $\alpha / \beta$-amyrin separately, and in combination, were chosen. Thus, a flask of culture $\mathrm{LLCMK}_{2}$ cells with a well-formed monolayer and previously infected with $1 \times 10^{7}$ trypomastigotes $\mathrm{mL}^{-1}$ was either treated or not with concentrations of the $\mathrm{IC}_{50}$ and $\mathrm{IC}_{90}$ of triterpenes for $24 \mathrm{~h}$. The cells were collected and fixed with $2.5 \%$ glutaraldehyde prepared in $0.1 \mathrm{M}$ cacodylate buffer, and the cell monolayer was detached and collected and, then, pos-fixed in $1 \%$ osmium tetroxide and $0.8 \%$ potassium ferrocyanide, prepared in a cacodylate buffer. The parasites were washed, and then dehydrated in growing concentrations of acetone (50, 70, 80, 90, 95 and $100 \%$ ), gradually embedded in Epon resin and polymerized at $60{ }^{\circ} \mathrm{C}$. Ultra-thin sections of the samples were obtained with an ultramicrotome cut and stained with uranyl acetate and lead citrate. A JEOL JM1400 transmission electron microscope was used to examine the ultrastructure of the parasites.

Evaluation of the mitochondrial membrane potential and cell membrane integrity

To associate the ultrastructural alterations with the action mechanisms of the triterpenes, both mitochondrial membrane potential $(\Delta \Psi \mathrm{m})$ and cell membrane integrity were evaluated in amastigotes treated with triterpenoids by using flow cytometry. The same five compounds and the higher synergistic combination found between $\alpha / \beta$-amyrin and 3-O-acetyl-11-oxo- $\alpha / \beta$-amyrin, assessed by electron microscopy were also assessed through the flow cytometry. Therefore, $T$. cruzi parasitic forms $\left(1 \times 10^{7}\right.$ amastigotes $\left.\mathrm{mL}^{-1}\right)$, either treated or not with the $\mathrm{IC}_{50}$ and $\mathrm{IC}_{90}$ for $24 \mathrm{~h}$ with five different compounds ( $\alpha / \beta$-amyrin, 3-O-phthaloyl- $\alpha / \beta$-amyrin, 3-O-acetyl11-oxo- $\alpha / \beta$-amyrin, 3- $O$-succinyl-11-oxo- $\alpha / \beta$-amyrin and lup-20(29)-en-3-one) and with the combination between $\alpha / \beta$-amyrin and 3-O-acetyl-11-oxo- $\alpha / \beta$-amyrin, were assessed with electron microscopy. The cell membrane integrity was evaluated by using PI (propidium iodide), a probe that binds to DNA (deoxyribonucleic acid) in ruptured membrane cells. After treatment, the parasites were washed and incubated with $0.2 \mathrm{mg} \mathrm{mL}^{-1} \mathrm{PI}$ for $10 \mathrm{~min}$ to verify the cell membrane integrity. Data acquisition and analysis were performed by using a FACSCalibur ${ }^{\mathrm{TM}}$ flow cytometer (Becton-Dickinson, Rutherford, NJ, USA) equipped with the CellQuest software (Joseph Trotter, The Scripps Research Institute, La Jolla, CA, USA). A total of 10,000 events were acquired in the previously established region that corresponds to the parasites. Alterations in the PI fluorescence were quantified as the increase percentage in the fluorescence compared with the control (untreated parasites). To evaluate the mitochondrial membrane potential $(\Delta \Psi \mathrm{m})$, the rhodamine 123 (Rh123) was used as a fluorescent probe, which accumulates within mitochondria. The amastigotes previously treated for $24 \mathrm{~h}$ were washed and incubated with $5 \mathrm{mg} \mathrm{mL} \mathrm{mL}^{-1} \mathrm{Rh} 123$ for $15 \mathrm{~min}$ to verify alterations in $\Delta \Psi \mathrm{m}$, and data acquisition was obtained with a flow 
cytometer. Changes in Rh123 fluorescence were quantified by using an index variation (IV) obtained by the equation (MT - MC) / MC, where MT is the median fluorescence for treated parasites and $\mathrm{MC}$ is the median fluorescence of control parasites. Negative IV values (-IV) correspond to the depolarization of the mitochondrial membrane and positive IV values (+IV), hypolarization process. The carbonyl cyanide 3-chlorophenylhydrazone (CCCP) with a dosage of $100 \mu \mathrm{M}$ was used as a positive control for the Rh123 experiments, and digitonin $(40 \mu \mathrm{M})$ was used as a positive control for the PI experiments.

\section{Cell volume determination}

The amastigotes $\left(1 \times 10^{7}\right.$ parasites $\left.\mathrm{mL}^{-1}\right)$ were treated for $24 \mathrm{~h}$ with $\mathrm{IC}_{50}$ and $\mathrm{IC}_{90}$ of $\alpha / \beta$-amyrin, 3- $O$-phthaloyl$\alpha / \beta$-amyrin, 3- $O$-acetyl-11-oxo- $\alpha / \beta$-amyrin, 3- $O$-succinyl11 -oxo- $\alpha / \beta$-amyrin and lup-20(29)-en-3-one, and the combination between $\alpha / \beta$-amyrin and 3-O-acetyl11 -oxo- $\alpha / \beta$-amyrin. The parasites were collected with centrifugation, washed twice in PBS, resuspended in PBS, and directly analyzed through fluorescence-activated cell sorting by using a BD FACSCalibur flow cytometer (Becton-Dickinson, Rutherford, NJ, USA). A total of 10,000 events were acquired in a region previously established for the parasites. The parasites treated with actinomycin $\mathrm{D}(20.0 \mathrm{mM})$ were used as a positive control. Histograms were generated and the analyses were performed by using the CellQuest software, in which the FSC (forward scatter) parameters represent the cell volume.

\section{Statistical analysis}

The experiments were carried out in different occasions, and the statistical analysis was performed with the GraphPad Prism 5.0 software with one-way analysis of variance (ANOVA) test. Values of $p<0.05$ were considered significant.

Ethics

For the hemolytic assay, voluntary donations of human blood were obtained according to the Declaration of Helsinki (Ethical principles for medical research involving human beings). The donors were informed about the purpose of the study and provided with the written consent before blood collection. The blood was collected through brachial vein puncture by a trained professional with appropriate material and medical support. All procedures were conducted as described in the specific protocol approved by the Ethics Committee on Human Beings of the State University of
Maringá (acceptance 293/2006 COPEP-UEM). In order to obtain tissue culture-derived trypomastigote forms, blood was weekly collected through cardiac puncture, the Swiss mice were obtained in the Central Animal Facility of the State University of Maringá (UEM). All the procedures were carried out in accordance with the guidelines established by the Ethics Committee on Animal Experiments of UEM, stating the detailed approved protocol for this experiment (acceptance 074/2011-CONCEA).

\section{Results}

Amyrins were obtained from Burseraceae family that produces Brazilian oil resins, such as the breu resin exudate that is obtained from species Protium hebetatum and $P$. paniculatum. These triterpenes are promising raw materials for the semi-synthesis of triterpene derivatives, since these compounds are easily purified and available in high amounts throughout Amazon region. ${ }^{25}$ However, the isomers are not easy to separate, ${ }^{26}$ and have usually been studied as a binary mixture, especially $\alpha$-amyrin and $\beta$-amyrin, from oleanane and ursane skeletons, respectively.

In the present study, seven derivatives were obtained from this binary mixture [(1) $\alpha / \beta$-amyrin]: (2) 3-O-fumaryl$\alpha / \beta$-amyrin, (3) 3- $O$-succinyl- $\alpha / \beta$-amyrin, (4) 3- $O$-acetyl$\alpha / \beta$-amyrin, (5) 3- $O$-ftaloyl- $\alpha / \beta$-amyrin, (6) 3- $O$-acetyl11-oxo- $\alpha / \beta$-amyrenone, (7) 3- $O$-acetyl-11-oxo- $\alpha / \beta$-amyrin and (8) 3- $O$-ftaloyl-11-oxo- $\alpha / \beta$-amyrin. To improve the discussion on SAR of the triterpenes, four natural triterpenes previously isolated were also studied: three pentacyclic lupane compounds [(9) lup-20(29)-en3-one, (10) 3 $3,6 \beta, 16 \beta$-trihydroxylup-20(29)-ene and (11) betulinic acid], together with a tetracyclic dammarane [(12) lanosta-8,24-dien-3-one]. All compounds were used to determine their trypanocidal activities and action mechanisms against trypomastigote and amastigote forms (Figure 1). The semi-synthesis reactions of triterpenic derivatives obtained by $\alpha / \beta$-amyrin are shown in Figure 2.

Activity against trypomastigote forms

In general, the treatment with triterpenoids was not effective in the nonproliferative forms of $T$. cruzi. For all the compounds, it was not observed 50\% activity against trypomastigotes even up to the assessed maximum concentration $(100 \mu \mathrm{M})$, except for compounds (2) 3-O-fumaryl- $\alpha / \beta$-amyrin, (3) 3-O-succinyl$\alpha / \beta$-amyrin and (5) 3-O-phthaloyl- $\alpha / \beta$-amyrin. Compounds (3) 3-O-succinyl- $\alpha / \beta$-amyrin and (5) 3-O-phthaloyl- $\alpha / \beta$-amyrin displayed a moderate activity with an $\mathrm{IC}_{50}$ values of 74.6 and $86.3 \mu \mathrm{M}$, respectively. Only 


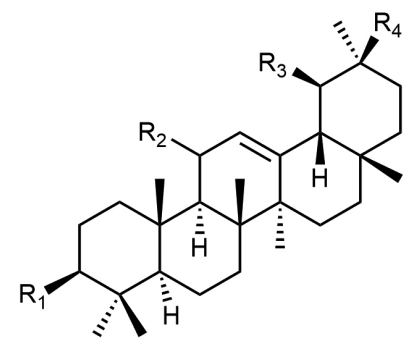
$\mathbf{R}_{1}$
$\mathbf{R}_{\mathbf{2}}$
$\mathbf{R}_{1}$
$\mathbf{R}_{\mathbf{2}}$
1
$\mathrm{HO}^{- \text {s. }}$.
$\mathrm{H}, \mathrm{H}$
5<smiles>[Z20]C(=O)c1ccccc1C(=O)O</smiles>
$\mathrm{H}, \mathrm{H}$
2<smiles>COC(=O)/C=C/C(=O)O</smiles>
$\mathrm{H}, \mathrm{H}$
6<smiles></smiles>
3<smiles>COC(=O)CCC(=O)O</smiles>
$\mathrm{H}, \mathrm{H}$
7<smiles>COC(=O)CCC(=O)O</smiles><smiles>C=O</smiles>
4<smiles>CC(=O)OC(C)=O</smiles>
$\mathrm{H}, \mathrm{H}$

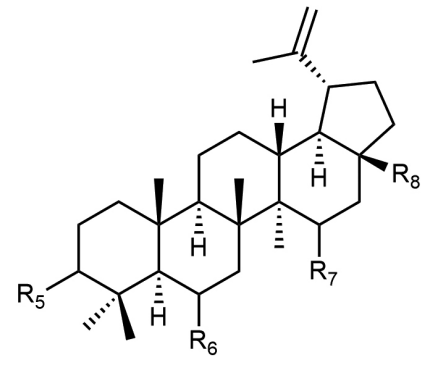
8<smiles>C=CCOC(=O)c1ccccc1C(=O)O</smiles><smiles>CC(C)=CCC[C@H](C)[C@H]1CC[C@]2(C)C3=C(CC[C@]12C)[C@@]1(C)CCC(=O)C(C)(C)C1CC3</smiles>
$\mathbf{R}_{\mathbf{5}}$
$\mathbf{R}_{6}$
$\mathbf{R}_{\mathbf{7}}$
$\mathbf{R}_{\mathbf{8}}$
12
$9 \mathrm{O}=\mathrm{H}, \mathrm{H} \quad \mathrm{H}, \mathrm{H} \quad \mathrm{CH}_{3}$
$10 \mathrm{H}, \mathrm{OH} \quad \mathrm{H}, \mathrm{OH} \quad \mathrm{H}, \mathrm{OH} \quad \mathrm{CH}_{3}$
$11 \mathrm{H}, \mathrm{OH} \quad \mathrm{H}, \mathrm{H} \quad \mathrm{H}, \mathrm{H} \quad \mathrm{COOH}$

Figure 1. Chemical structures of the triterpenes tested for trypanocidal activity: (1) $\alpha / \beta$-amyrin, (2) 3- $O$-fumaryl- $\alpha / \beta$-amyrin, (3) 3- $O$-succinyl- $\alpha / \beta$-amyrin, (4) 3- $O$-acetyl- $\alpha / \beta$-amyrin, (5) 3- $O$-phthaloyl- $\alpha / \beta$-amyrin, (6) 3- $O$-acetyl-11-oxo- $\alpha / \beta$-amyrin, (7) 3- $O$-succinyl-11-oxo- $\alpha / \beta$-amyrin, (8) 3- $O$-phthaloyl11-oxo- $\alpha / \beta$-amyrin, (9) lup-20(29)-en-3-one, (10) lup-20(29)-ene-3 $\beta, 6 \beta, 15 \beta$-triol, (11) betulinic acid and (12) lanosta-8,24-dien-3-one; $\alpha$ isomer: $\mathrm{R}_{3}=\mathrm{CH}_{3}$, $\mathrm{R}_{4}=\mathrm{H} ; \beta$ isomer: $\mathrm{R}_{3}=\mathrm{H}, \mathrm{R}_{4}=\mathrm{CH}_{3}$.

the compound (2) 3-O-fumaryl- $\alpha / \beta$-amyrin exhibited a good activity, with an $\mathrm{IC}_{50}$ of $25.2 \mu \mathrm{M}$ (Table 1).

\section{Activity against amastigote forms}

Unlike the antitrypomastigote activity, all triterpenoid compounds exhibited an excellent activity, inhibiting the parasite intracellular multiplication. After $96 \mathrm{~h}$, only compound (6) 3-O-acetyl-11-oxo- $\alpha / \beta$-amyrin showed a moderate activity with an $\mathrm{IC}_{50}$ of $55.3 \mu \mathrm{M}$, and among the other eleven triterpenes, the $\mathrm{IC}_{50}$ values varied from 3.2 to $21.8 \mu \mathrm{M}$. Based on the $\mathrm{CC}_{50}$ and $\mathrm{IC}_{50}$ values, the SI was determined to compare toxicity for the parasite when compared to the host cells. The higher selectivity indexes indicate more toxicity to the protozoan than mammalian cells. Compounds (5) 3-O-phthaloyl- 


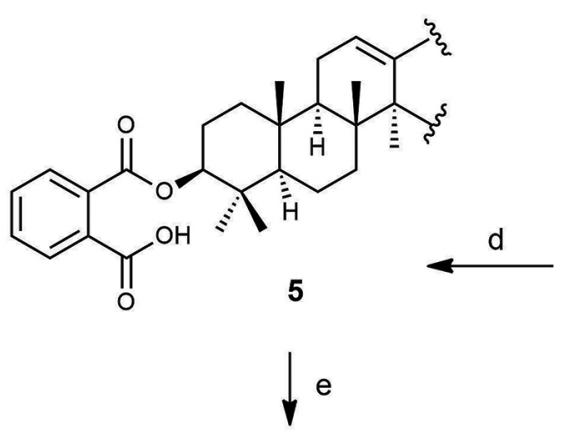<smiles>CCC1=CCC2[C@]3(C)CC[C@@H](O)C(C)(C)[C@H]3CC[C@@]2(C)[C@H]1C(C)C</smiles>

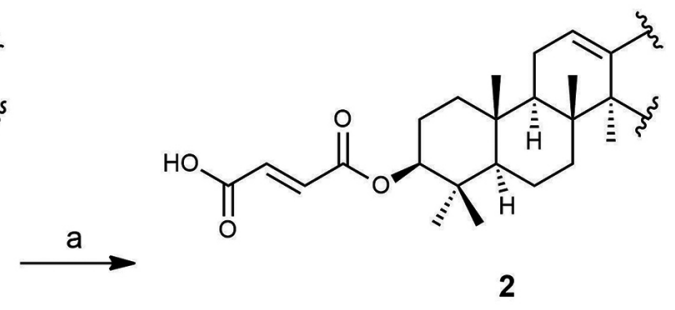

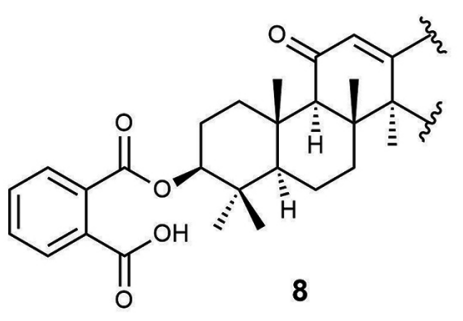

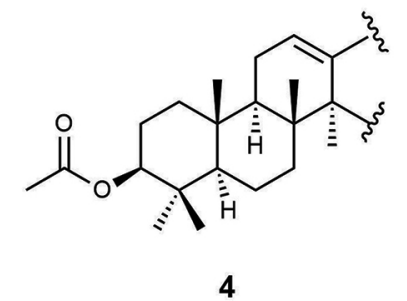

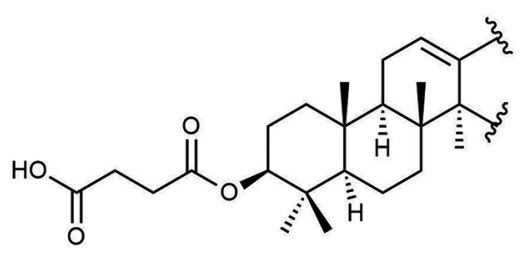

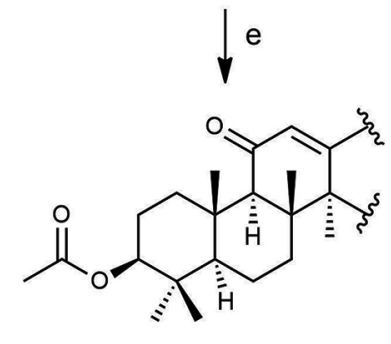

6

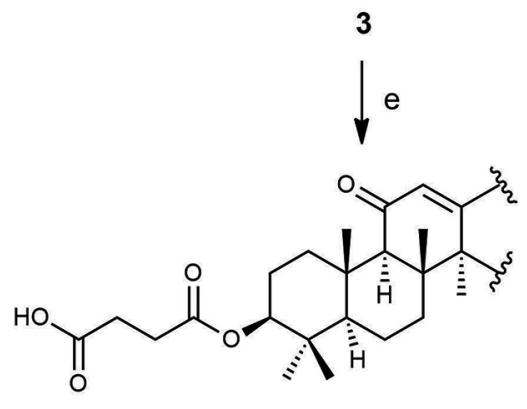

Figure 2. Semi-synthesis of triterpene derivatives, reagents and conditions: (a) maleic anhydride, $\mathrm{DMAP}, \mathrm{CH}_{2} \mathrm{Cl}_{2}$, reflux, 24 h; (b) succinic anhydride, DMAP, $\mathrm{CH}_{2} \mathrm{Cl}_{2}$, reflux, $24 \mathrm{~h}$; (c) acetic anhydride, DMAP, reflux, $30 \mathrm{~min}$; (d) phthalic anhydride, $\mathrm{DMAP}, \mathrm{CH}_{2} \mathrm{Cl}_{2}$, reflux, $24 \mathrm{~h}$; and (e) acetic anhydride, acetic acid, tert-butyl chromate, reflux, $6 \mathrm{~h}$.

Table 1. Trypanocidal activity and cytotoxicity on mammalian cells of twelve triterpenoid compounds (with standard deviation): (1) $\alpha / \beta$-amyrin, (2) 3- $O$-fumaryl- $\alpha / \beta$-amyrin, (3) 3- $O$-succinyl- $\alpha / \beta$-amyrin, (4) 3- $O$-acetyl- $\alpha / \beta$-amyrin, (5) 3- $O$-phthaloyl- $\alpha / \beta$-amyrin, (6) 3- $O$-acetyl-11-oxo- $\alpha / \beta$-amyrin, (7) 3- $O$-succinyl-11-oxo- $\alpha / \beta$-amyrin, (8) 3- $O$-phthaloyl-11-oxo- $\alpha / \beta$-amyrin, (9) lup-20(29)-en-3-one, (10) lup-20(29)-ene-3 $\beta, 6 \beta, 15 \beta$-triol, (11) betulinic acid and (12) lanosta-8,24-dien-3-one

\begin{tabular}{|c|c|c|c|c|c|}
\hline \multirow{2}{*}{ Compound } & Trypomastigote & Amastigote & $\mathrm{LLCMK}_{2}$ & Erytrocyte & SI \\
\hline & $\mathrm{EC}_{50}(24 \mathrm{~h}) / \mu \mathrm{M}$ & $\mathrm{IC}_{50}(96 \mathrm{~h}) / \mu \mathrm{M}$ & $\mathrm{CC}_{50}(96 \mathrm{~h}) / \mu \mathrm{M}$ & $\mathrm{H}(3 \mathrm{~h}) / \%$ & $\mathrm{CC}_{50} / \mathrm{IC}_{50}$ \\
\hline 1 & $>100$ & $20.2 \pm 2.0$ & $136.3 \pm 7.7$ & $8.6 \pm 1.1$ & 6.7 \\
\hline 2 & $25.2 \pm 0.6$ & $3.2 \pm 0.6$ & $16.2 \pm 1.1$ & $51.1 \pm 0.3$ & 5.1 \\
\hline 3 & $86.3 \pm 1.3$ & $10.1 \pm 1.8$ & $150.4 \pm 4.3$ & $3.4 \pm 1.3$ & 14.9 \\
\hline 4 & $>100$ & $21.2 \pm 4.9$ & $135.8 \pm 6.2$ & $12.6 \pm 1.2$ & 6.4 \\
\hline 5 & $74.6 \pm 3.8$ & $6.1 \pm 2.9$ & $104.6 \pm 2.5$ & $27.5 \pm 3.4$ & 17.1 \\
\hline 6 & $>100$ & $55.3 \pm 4.0$ & $103.6 \pm 6.7$ & $5.5 \pm 3.2$ & 1.9 \\
\hline 7 & $>100$ & $9.7 \pm 1.4$ & $195.5 \pm 5.9$ & $23.0 \pm 1.4$ & 20.2 \\
\hline 8 & $>100$ & $9.7 \pm 3.0$ & $150.3 \pm 5.5$ & $82.4 \pm 1.9$ & 15.5 \\
\hline 9 & $>100$ & $21.8 \pm 4.2$ & $556.5 \pm 11.3$ & $5.1 \pm 1.6$ & 25.5 \\
\hline 10 & $>100$ & $5.9 \pm 0.2$ & $29.6 \pm 0.7$ & $24.0 \pm 0.4$ & 5.0 \\
\hline 11 & $>100$ & $9.9 \pm 0.1$ & $102.2 \pm 3.6$ & $25.7 \pm 1.4$ & 10.4 \\
\hline 12 & $>100$ & $11.0 \pm 5.5$ & $137.1 \pm 7.2$ & $10.5 \pm 2.2$ & 12.5 \\
\hline $\mathrm{Bz}$ & $5.1 \pm 2.1$ & $9.3 \pm 0.9$ & $1,235.3 \pm 15.1$ & $49.5 \pm 3.4$ & 132.8 \\
\hline
\end{tabular}

Values of concentration are represented in $\mu \mathrm{M}$. $\mathrm{IC}_{50}$ : inhibitory concentration of $50 \%$; $\mathrm{EC}_{50}$ : effective concentration of $50 \%$; $\mathrm{CC}_{50}$ : cytotoxic concentration of $50 \%$; H: percentage of hemolysis at concentration of $2000 \mu \mathrm{M}$; SI: selectivity index between $\mathrm{LLCMK}_{2}$ cells and amastigote forms; significant differences between activity of the compounds and control cell growth, ANOVA $(p<0.0001)$. 
$\alpha / \beta$-amyrin, (7) 3-O-succinyl-11-oxo- $\alpha / \beta$-amyrin and (9) lup-20(29)-en-3-one were 17.1 to 25.5 -fold more active against amastigotes than the host cells. The compounds (2) 3- $O$-fumaryl- $\alpha / \beta$-amyrin, (6) 3- $O$-acetyl-11-oxo$\alpha / \beta$-amyrin and (10) lup-20(29)-ene-3 $\beta, 6 \beta, 15 \beta$-triol were the least selective, with SIs of 5.1, 1.9, and 5.0 (Table 1). Comparing the triterpenoids' antiamastigote activity with benznidazole, the standard drug displayed an $\mathrm{IC}_{50}$ of $9.3 \mu \mathrm{M}$ to the intracellular parasites of the vertebrate host cells.

\section{Cytotoxicity in mammalian cells}

Most the triterpenes displayed a low cytotoxicity against the mammalian host cells $\left(\mathrm{LLCMK}_{2}\right)$ incubated for $96 \mathrm{~h}$. The most toxic compounds were (2) 3-O-fumaryl$\alpha / \beta$-amyrin and (10) lup-20(29)-ene-3 $3,6 \beta, 15 \beta$-triol with $\mathrm{CC}_{50}$ values of 16.2 and $29.6 \mu \mathrm{M}$, respectively, and the lowest toxic compound was (9) lup-20(29)-en-3-one with a $\mathrm{CC}_{50}$ of $556.5 \mu \mathrm{M}$. Among the nine remaining triterpenes, the lowest toxic compounds were observed with a $\mathrm{CC}_{50}$, which ranged from 102.2 to $195.5 \mu \mathrm{M}$. The benznidazole demonstrated the lowest toxicity in relation to the triterpenes. The toxicity in erythrocytes was lower than nucleated cells. After $3 \mathrm{~h}$, the hemolysis rate for the lowest hemolytic compounds varied from 3.4 to $27.5 \%$ with the highest tested concentration $(2.000 \mu \mathrm{M})$. However, the compounds (2) 3-O-fumaryl$\alpha / \beta$-amyrin and (8) 3-O-phthaloyl-11-oxo- $\alpha / \beta$-amyrin showed the highest hemolytic activity with 51.1 and $82.4 \%$ of hemolysis rate (Table 1).

\section{Drug combination assay}

Because of the higher antimastigote activity of the triterpenes, the aim of this study was to evaluate the drug combination assay only in intracellular forms. The evaluation of the combinatorial effects with combination of the compounds (1) $\alpha / \beta$-amyrin and (6) 3- $O$-acetyl-11-oxo$\alpha / \beta$-amyrin revealed a synergistic activity with a CI of 0.78 .
In addition, the combination of (4) 3-O-acetyl- $\alpha / \beta$-amyrin and benznidazole also showed synergistic interaction with a CI of 0.81. The above described combinations were also performed in $\mathrm{LLCMK}_{2}$ cells to verify variation on cells. Satisfactory results were also obtained because both combinations exhibited antagonistic effects in $\mathrm{LLCMK}_{2}$ cells, with a CI of 1.35 and 1.4, respectively (Figure 3 ).

\section{Ultrastructural and morphological alterations}

TEM images of the intracellular replicative amastigotes treated with triterpenoids revealed morphological alterations due to the lack of uniformity of the plasma membrane (white arrow head, Figures 4 and 5). Furthermore, alterations were observed in the ultrastructure mitochondrionkinetoplast complex (Figures 4C, E and F, and Figure 5E), including rupture of the mitochondrion (white star, Figure 4E), multiple cytoplasmic vacuolization structures (Figure 5B) that accumulate lipids in these inclusions (white star, Figure 5C) and a formation of the membrane within the kinetoplast (black arrow head, Figure 5E). The most evident feature observed in treated-amastigotes was an induction of the formation of autophagosomes (black arrow, Figures 4 and 5) and autophagosome-like structures such as: well-developed endoplasmic reticulum (white arrow, Figures 4 and 5), which surrounds cytoplasmic structures and organelles, Golgi complex extension (white arrow head, Figure 5C) and concentric myelin-like membrane structures (black arrow head, Figure 4G).

Evaluation of the mitochondrial membrane potential and cell membrane integrity

For the cell membrane integrity assay, alterations were not verified in the membrane permeability in T. cruzi intracellular forms through the incubation with triterpenoids. The low number of high fluorescence events (upper left and upper right quadrants) shows cells with
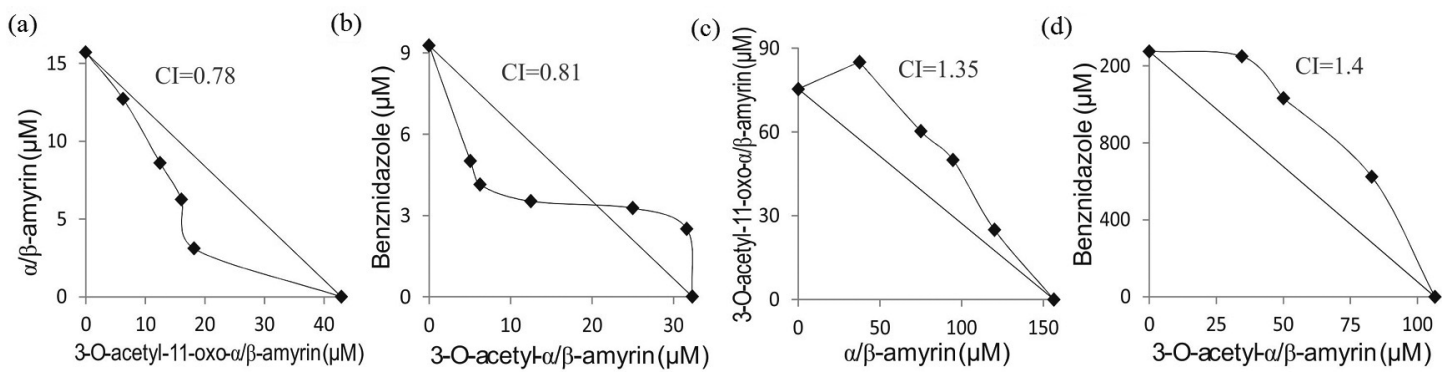

Figure 3. Combinatorial effects between (1) $\alpha / \beta$-amyrin with (6) 3-O-acetyl-11-oxo- $\alpha / \beta$-amyrin and benznidazole with (4) 3-O-acetyl- $\alpha / \beta$-amyrin on amastigotes of $T$. cruzi and $\mathrm{LLCMK}_{2}$ cells. Isobolograms (a) and (b) show the combinatorial effects of (1) $\alpha / \beta$-amyrin with (6) 3-O-acetyl-11-oxo$\alpha / \beta$-amyrin and (4) 3-O-acetyl- $\alpha / \beta$-amyrin with benznidazole against amastigotes, respectively; (c) and (d) illustrate combination between (1) $\alpha / \beta$-amyrin with (6) 3-O-acetyl-11-oxo- $\alpha / \beta$-amyrin and (4) 3-O-acetyl- $\alpha / \beta$-amyrin with benznidazole on $\mathrm{LLCMK}_{2}$ cells, respectively. Points below the additivity effect line indicate a synergistic effect and above indicate an antagonistic effect (combination index (CI)). 

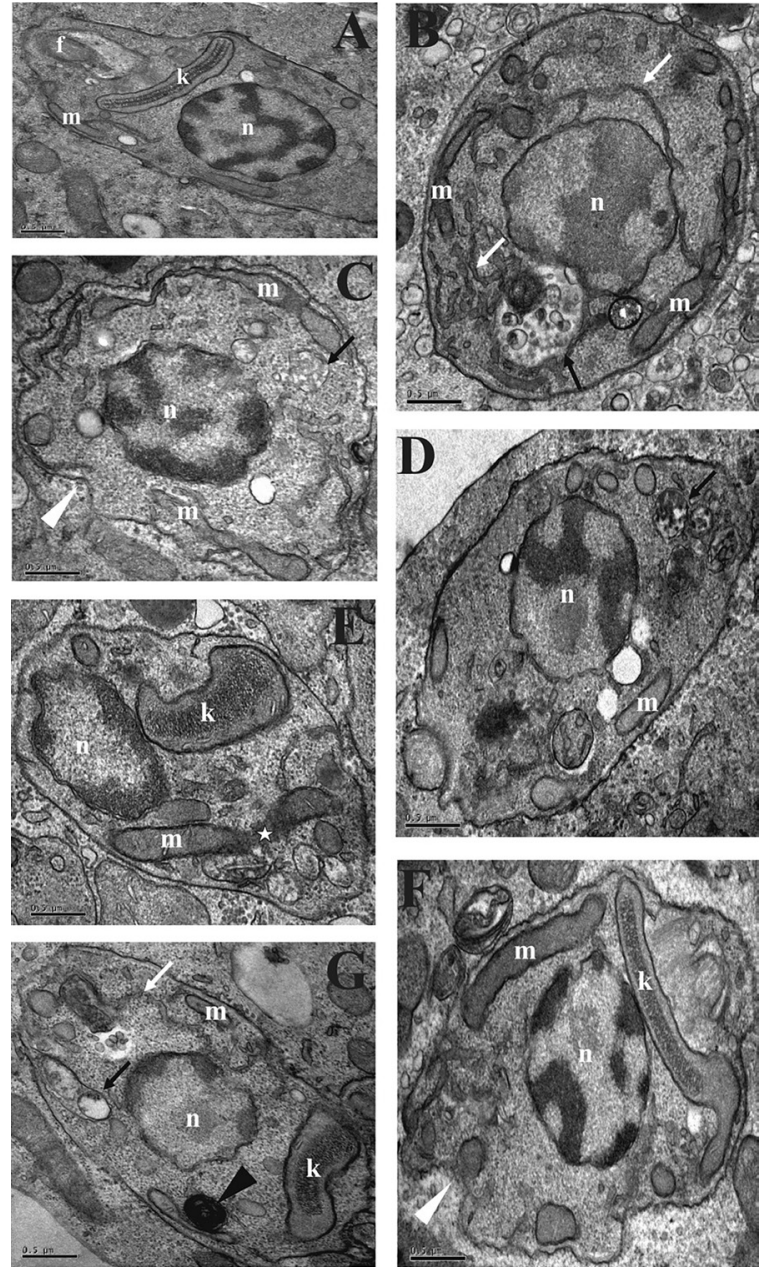

Figure 4. Transmission electron images of amastigotes forms of T. cruzi treated with triterpenes for $24 \mathrm{~h}$. (A) Control; (B)-(G) correspond to treated-amastigotes with $\mathrm{IC}_{50}$ of the compounds $(\mathbf{1}) \alpha / \beta$-amyrin $(20.2 \mu \mathrm{M}),(5) 3-O$-phthaloyl- $\alpha / \beta$-amyrin $(6.1 \mu \mathrm{M})$, (6) 3- $O$-acetyl11-oxo- $\alpha / \beta$-amyrin $(55.3 \mu \mathrm{M})$, (7) 3- $O$-succinyl-11-oxo- $\alpha / \beta$-amyrin $(9.7 \mu \mathrm{M}),(9)$ lup-20(29)-en-3-one $(21.8 \mu \mathrm{M})$, and drug combination between (1) $\alpha / \beta$-amyrin $(7.1 \mu \mathrm{M})$ with (6) 3-O-acetyl-11-oxo- $\alpha / \beta$-amyrin $(14.5 \mu \mathrm{M})$, respectively; $\mathrm{n}$ : nucleus, $\mathrm{k}$, kinetoplast, $\mathrm{m}$, mitochondrion, and f, flagellum. Bar $=1 \mu \mathrm{m}$.

normal membrane permeability due to blockage of the entrance of PI inside the cells. In the three experiments with amastigote forms, the effects of the treatment with triterpenes with $\mathrm{IC}_{50}$ and $\mathrm{IC}_{90}$ were very similar to those untreated parasites (Figure 6). The digitonin (positive control) promoted a loss of the cell membrane integrity with $93.9 \%$ PI-stained positive cells in the upper left and upper right quadrants.

Differently from the assay above described, some alterations were verified in $\Delta \Psi \mathrm{m}$. The histograms showed a decrease in total Rh123 fluorescence intensity for all the compounds mainly treated with $\mathrm{IC}_{90}$, thus resulting in a mitochondrial depolarization. However, (1) $\alpha / \beta$-amyrin combined (6) 3- $O$-acetyl-11-oxo- $\alpha / \beta$-amyrin with $\mathrm{IC}_{50}$ that showed an enhancement of the total $\mathrm{Rh} 123$
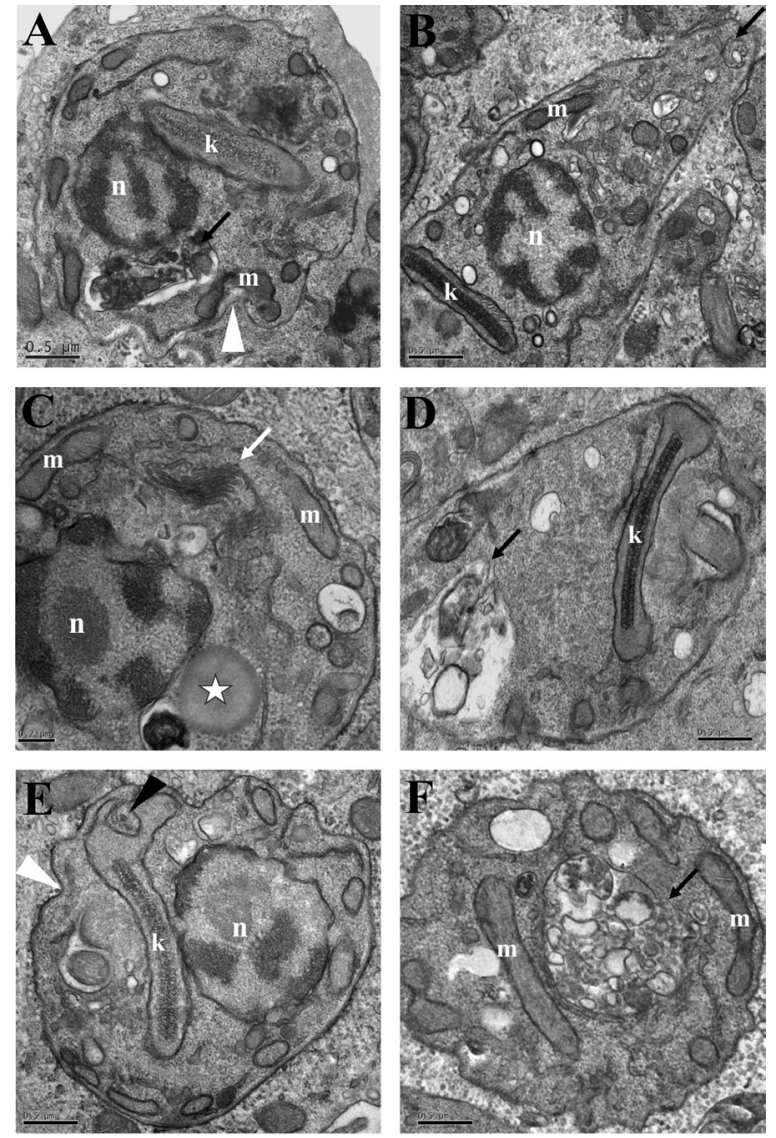

Figure 5. Transmission electron images of amastigotes forms of T. cruzi treated with triterpenes for $24 \mathrm{~h}$. (A)-(F) correspond to treatedamastigote with an $\mathrm{IC}_{90}$ of the compounds $(\mathbf{1}) \alpha / \beta$-amyrin $(97.3 \mu \mathrm{M})$, (5) 3- $O$-phthaloyl- $\alpha / \beta$-amyrin $(86.3 \mu \mathrm{M}),(6) 3$ - $O$-acetyl-11-oxo$\alpha / \beta$-amyrin $(112.5 \mu \mathrm{M})$, (7) 3-O-succinyl-11-oxo- $\alpha / \beta$-amyrin $(90.6 \mu \mathrm{M})$, (9) lup-20(29)-en-3-one $(95.9 \mu \mathrm{M})$, and drug combination between (1) $\alpha / \beta$-amyrin $(38.3 \mu \mathrm{M})$ with (6) 3 - $O$-acetyl-11-oxo- $\alpha / \beta$-amyrin $(47.2 \mu \mathrm{M})$, respectively. Key: n, nucleus, k, kinetoplast, and m, mitochondrion. $\mathrm{Bar}=1 \mu \mathrm{m}$.

fluorescence, which indicates a mitochondrial membrane hyperpolarization (Figure 7). CCCP caused a high Rh123 fluorescence intensity reduction in comparison to untreated cells (data not shown). In general, the treated-amastigotes with $\mathrm{IC}_{90}$ dosage of the triterpenoids displayed higher indexes of IV values than $\mathrm{IC}_{50}$, indicating dose-dependent effects. According to the higher IV values, treatment with (1) $\alpha / \beta$-amyrin and (6) 3- $O$-acetyl-11-oxo- $\alpha / \beta$-amyrin combined with $\mathrm{IC}_{90}$ (Table 2) was the most pronounced mitochondrial depolarization.

\section{Cell volume determination}

The amastigote forms treated with triterpenes, as previously described, were analyzed for FSC parameters through the flow cytometry. The positive control showed a substantial cell volume reduction by a decrease of the fluorescence intensity in the FSC parameters (data 

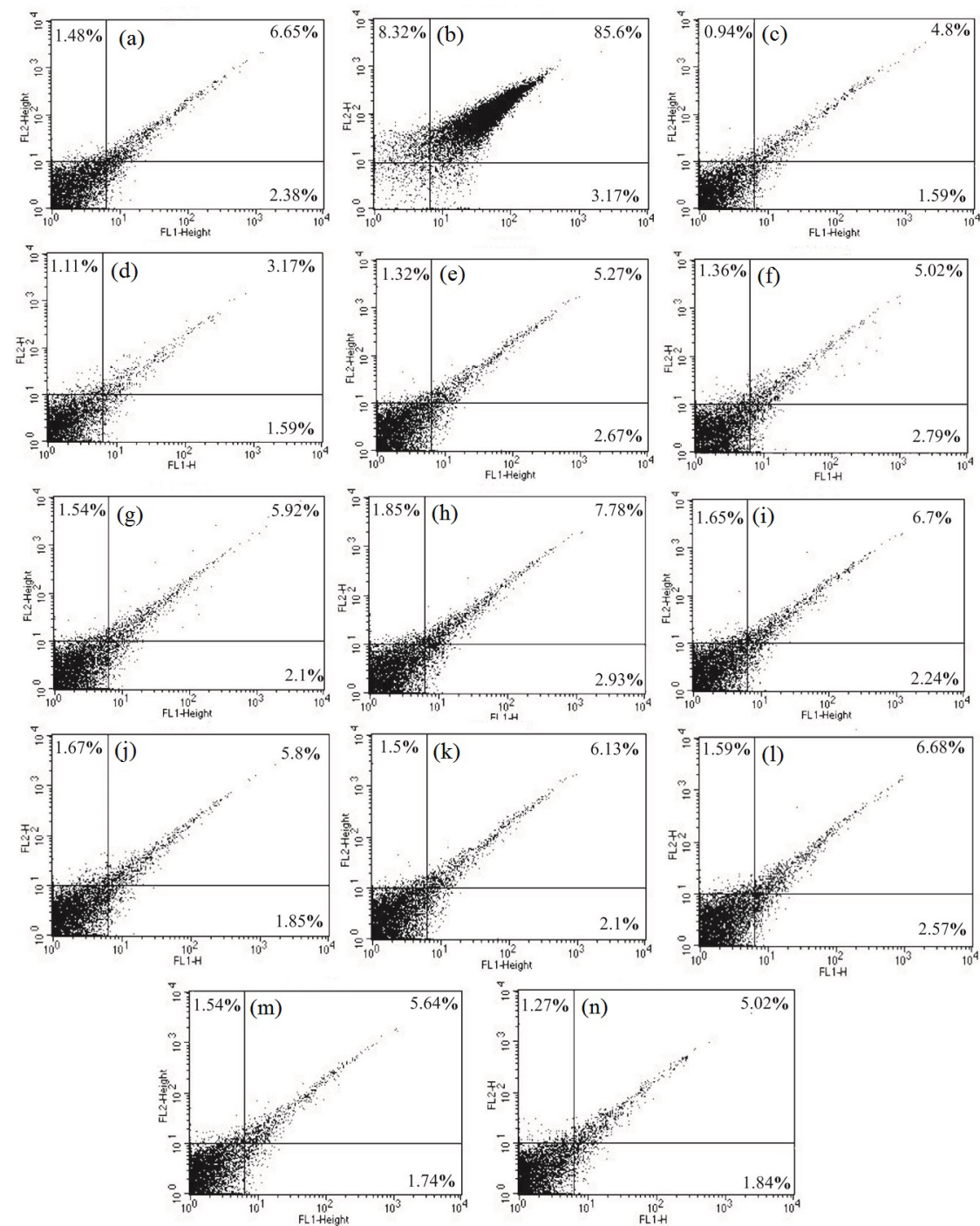

Figure 6. Cell membrane integrity assay by flow cytometry in amastigote forms of $T$. cruzi treated with triterpenes for $24 \mathrm{~h}$ and stained with PI. (a) Untreated amastigotes; (b) positive control; histograms (c), (e), (g), (i) (k) and (m) correspond to treated-amastigotes with $\mathrm{IC}_{50}$, and (d), (f), (g), (h), (j) (l) and (n) treated-amastigotes with $\mathrm{IC}_{90}$ of the compounds (1) $\alpha / \beta$-amyrin, (5) 3- $O$-phthaloyl- $\alpha / \beta$-amyrin, (6) 3- $O$-acetyl-11-oxo- $\alpha / \beta$-amyrin, (7) 3- $O$-succinyl11 -oxo- $\alpha / \beta$-amyrin, (9) lup-20(29)-en-3-one and drug combination between (1) $\alpha / \beta$-amyrin with (6) 3- $O$-acetyl-11-oxo- $\alpha / \beta$-amyrin, respectively. Percentage of PI-stained positive cells is shown in the upper right and left quadrants. Typical histograms of at least three independent experiments are shown.

not shown). As illustrated in Figure 8, the cell volume maintenance was observed by two concentrations $\left(\mathrm{IC}_{50}\right.$ and $\mathrm{IC}_{90}$ ) tested for mammalian stage T. cruzi parasites with five selected compounds and for the (1) $\alpha / \beta$-amyrin with (6) 3-O-acetyl-11-oxo- $\alpha / \beta$-amyrin in combination. All histograms showed a similar effect compared with the untreated control group for all the compounds and two selected concentrations by maintaining the fluorescence intensity in the FSC parameters.

\section{Discussion}

Considering modern drug research, natural products and plant-derivative terpenoids may offer good sources designs and discoveries for a new drug. In this study, the treatment with triterpenoids and benznidazole displayed an excellent anti-T. cruzi activity against the relevant clinically intracellular amastigote forms, which are responsible for the chronic phase infection maintenance through parasite persistence and parasite load in target organs. ${ }^{21,41}$ These features revealed to be crucial even at asymptomatic phase, since the host can develop autoimmunity due to the presence of the parasite. ${ }^{42}$ Thus, the aim of treatment in this stage should eliminate the amastigotes or reduce the parasite load. The weaker antitrypomastigote activity observed in this study with terpenes is well-reported in several previous researches. ${ }^{11-17,42,43}$

Several investigations relate that terpenes may arrest the cell division cycle and, in turn avoiding the parasite 

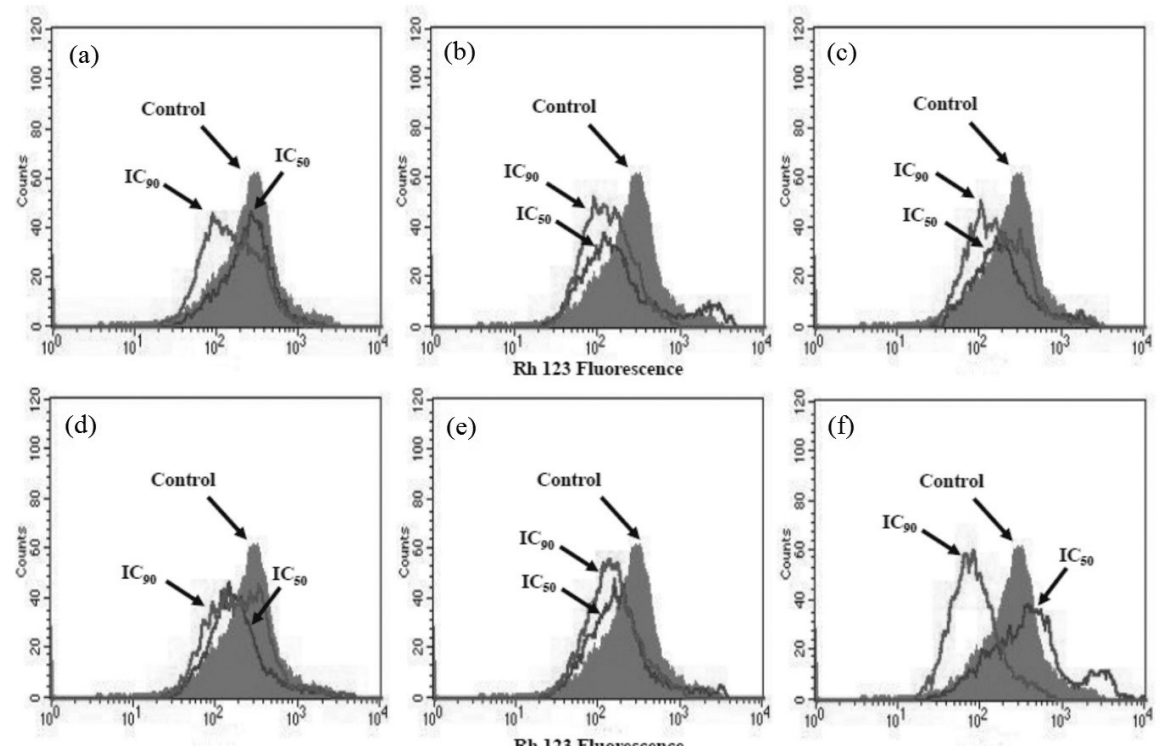

Figure 7. Mitochondrial membrane potential assay in amastigote forms of $T$. cruzi treated with $\mathrm{IC}_{50}$ and $\mathrm{IC}_{90}$ of the triterpenes for $24 \mathrm{~h}$ and stained with Rh123. (a)-(f) Amastigotes treated with triterpenoids (1) $\alpha / \beta$-amyrin, (5) 3- $O$-phthaloyl- $\alpha / \beta$-amyrin, (6) 3-O-acetyl-11-oxo- $\alpha / \beta$-amyrin, (7) 3- $O$-succinyl11-oxo- $\alpha / \beta$-amyrin, (9) lup-20(29)-en-3-one and drug combination between (1) $\alpha / \beta$-amyrin with (6) 3 - $O$-acetyl-11-oxo- $\alpha / \beta$-amyrin, respectively. Arrows correspond to the concentration tested and control group (untreated parasites) that are also shown. Typical histograms of at least three independent experiments are presented.

Table 2. Mitochondrial potential assay in parasitic forms of Trypanosoma cruzi treated with following triterpenoids for $24 \mathrm{~h}$ and stained with Rh123: (1) $\alpha / \beta$-amyrin, (5) 3- $O$-phthaloyl- $\alpha / \beta$-amyrin, (6) 3- $O$-acetyl-11-oxo- $\alpha / \beta$-amyrin, (7) 3- $O$-succinyl-11-oxo- $\alpha / \beta$-amyrin, (9) lup-20(29)-en-3-one and drug combination between (1) $\alpha / \beta$-amyrin with (6) 3-O-acetyl-11-oxo- $\alpha / \beta$-amyrin

\begin{tabular}{|c|c|c|c|c|}
\hline \multirow{2}{*}{ Compound } & \multicolumn{2}{|c|}{ Median of the fluorescence (Rdh 123) } & \multicolumn{2}{|c|}{$\mathrm{IV}^{\mathrm{a}}$} \\
\hline & $\mathrm{IC}_{50} / \mu \mathrm{M}$ & $\mathrm{IC}_{90} / \mu \mathrm{M}$ & $\mathrm{IC}_{50} / \mu \mathrm{M}$ & $\mathrm{IC}_{90} / \mu \mathrm{M}$ \\
\hline 1 & 165.5 & 134.5 & -0.3 & -0.5 \\
\hline 5 & 155.4 & 135.8 & -0.4 & -0.5 \\
\hline 6 & 160.2 & 143.8 & -0.4 & -0.4 \\
\hline 7 & 116.2 & 136.2 & -0.5 & -0.5 \\
\hline 9 & 140.8 & 120.8 & -0.4 & -0.5 \\
\hline $1+6$ & 355.5 & 77.0 & +0.4 & -0.7 \\
\hline Control & 250.3 & 250.3 & 0.0 & 0.0 \\
\hline
\end{tabular}

${ }^{\mathrm{a}} \mathrm{IV}=(\mathrm{MT}-\mathrm{MC}) / \mathrm{MC}$, where MT corresponds to the median of the fluorescence for treated parasites and MC for control parasites; Rh123: rhodamine 123; $\mathrm{IC}_{50}$ : inhibitory concentration of $50 \%$; IIV: index variation; -IV: negative IV values; +IV: positive IV values; $\mathrm{C}_{90}$ : inhibitory concentration of $90 \%$.

proliferation. Lozano et al.$^{44,45}$ reported a more triterpenoid resistence against trypomastigote forms may be related with their non-multiplying capacity. Despite the low antitrypomastigote activity, these compounds are promising candidates for therapeutic targets in the chronic stage. It is well-known that benznidazole displays a limited effectiveness for the chronic stage; even being the best current available drug in the market.

Aiming to obtain compounds with synergistic properties against chronic illness, great interactions were obtained with synergic activities by combining (1) $\alpha / \beta$-amyrin with (6) 3-O-acetyl-11-oxo- $\alpha / \beta$-amyrin, as well as (4) 3- $O$-acetyl- $\alpha / \beta$-amyrin combined with the standard drug benznidazole against intracellular forms. Additionally, these two combinations were performed in $\mathrm{LLCMK}_{2}$, and antagonism effects were obtained that indicate a satisfactory reduction of toxicity in the mammalian cells. In a recent study, Izumi et al. ${ }^{12}$ evaluated the combinational effects against trypomastigotes between copalic acid and $\beta$-caryophyllene in which a strong synergism was found with FICI (fractional inhibitory concentration index) values of 0.12. In addition, combination therapies with benznidazole can allow the decrease of the dosage of the standard drug for treating Chagas' disease and, thus, its side-effects might be alleviated and may extend the period of the treatment with benznidazole. ${ }^{21}$ The lowest 

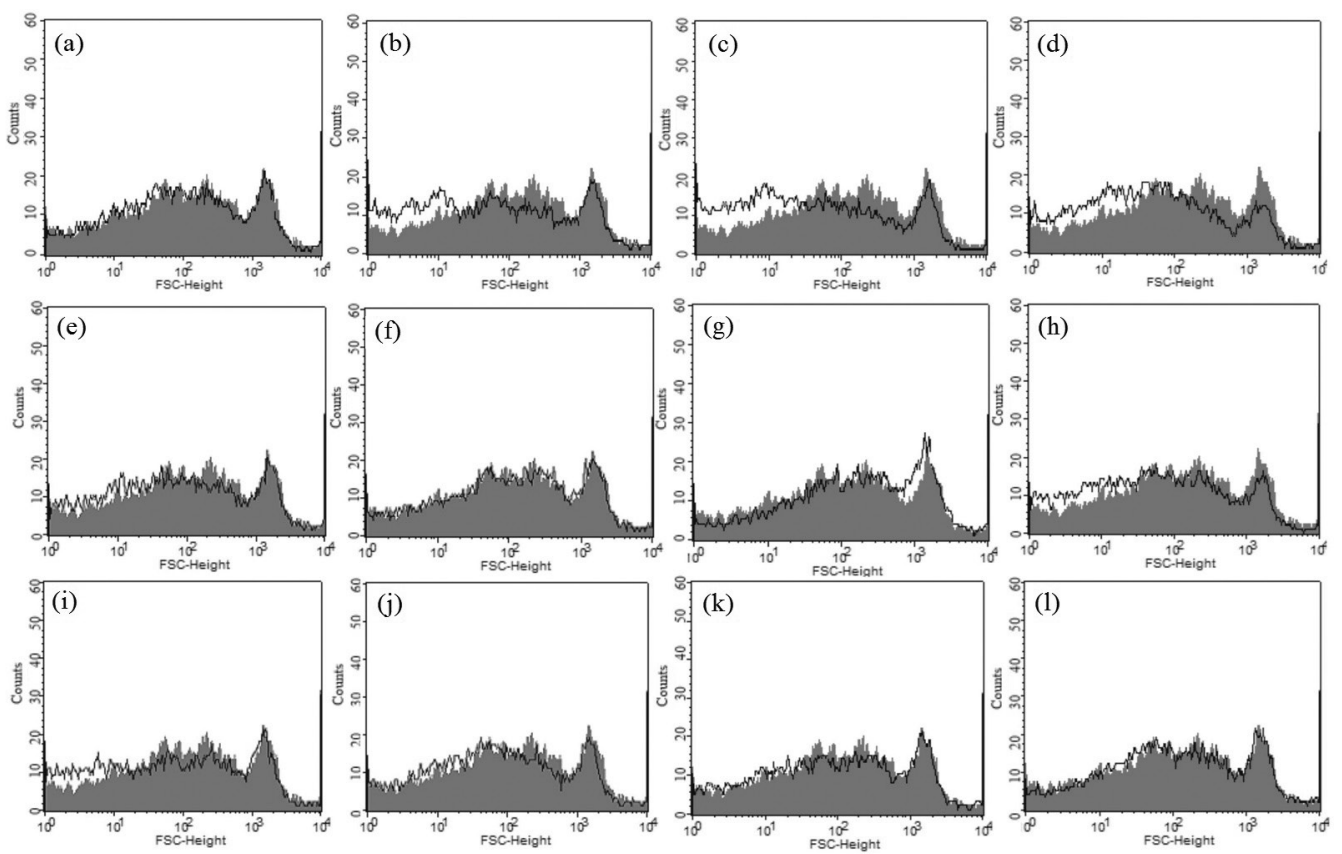

Figure 8. Cell volume determination of amastigotes treated with triterpenoids for $24 \mathrm{~h}$ and analyzed by flow cytometer. The histograms show the relationship between the number of cells (counts) and FSC considered as a function of cell size. Gray-filled areas represent untreated cells. In each plot, the black line with unfilled areas represents treated-parasites. Histograms (a), (c), (e) (g), (i) and (k) correspond to treated-amastigotes with $\mathrm{IC}_{50}$ and (b), (d), (f), (h), (j) and (1) treated-amastigotes with $\mathrm{IC}_{90}$ of the compounds (1) $\alpha / \beta$-amyrin, (5) 3-O-phthaloyl- $\alpha / \beta$-amyrin, (6) 3-O-acetyl-11-oxo- $\alpha / \beta$-amyrin, (7) 3- $O$-succinyl11-oxo- $\alpha / \beta$-amyrin, (9) lup-20(29)-en-3-one and drug combination between (1) $\alpha / \beta$-amyrin with (6) 3- $O$-acetyl-11-oxo- $\alpha / \beta$-amyrin, respectively.

cytotoxicity of benznidazole in vitro demonstrated in this study does not occur in vivo.

Toxicity data indicated that (9) lup-20(29)-en-3-one is one of the less toxic compounds, and (2) 3-O-fumaryl$\alpha / \beta$-amyrin and (10) lup-20(29)-ene-3 $\beta, 6 \beta, 15 \beta$-triol showed the strongest toxicity to $\operatorname{LLCMK}_{2}$ cells. The other compounds exhibited low and similar toxicities. Additionally, all the compounds tested showed non-toxicity properties in blood erythrocytes at very high concentrations of $2.000 \mu \mathrm{M}$, even though the compounds (2) 3-O-fumaryl$\alpha / \beta$-amyrin and (8) 3-O-phthaloyl-11-oxo- $\alpha / \beta$-amyrin displayed high hemolysis rates. It has already been reported that ursane, lupane- and oleanane-type triterpenes are considered as relatively non-toxic drugs. ${ }^{46}$ Furthermore, it has been reported that some natural pentacyclic triterpenoid derivatives such as oleanolic, ursolic and betulinic acids are a thousand-fold more active than the natural compounds. ${ }^{45}$ Based on this study, four compounds were the most selective to the protozoan [(5) 3-O-phthaloyl- $\alpha / \beta$-amyrin, (6) 3- $O$-succinyl-11-oxo- $\alpha / \beta$-amyrin, (8) 3- $O$-phthaloyl11 -oxo- $\alpha / \beta$-amyrin and (9) lup-20(29)-en-3-one], only (9) lup-20(29)-en-3-one is a natural isolated compound, and other compounds are triterpenic derivative, thereby promising compounds may be obtained by chemical derivatization.

Aiming to establish the SAR, it may be suggested that the more insertion of polar groups in the fundamental triterpenic core and the position insertion of these radicals is determinant for the activity. For instance, comparing the four ursane and oleanane-type triterpenoid derivatived from triterpenoid mixture of (1) $\alpha / \beta$-amyrin, it may be observed that (1) $\alpha / \beta$-amyrin was the less effective and (2) 3-O-fumaryl- $\alpha / \beta$-amyrin was the highest active from the twelve triterpenoids assessed against two T. cruzi developmental forms in the host and $\mathrm{LLCMK}_{2}$ cells. These data can be explained by an insertion of a radical 3-O-fumaryl at $\mathrm{C}-3$ position for (2) 3-O-fumaryl- $\alpha / \beta$-amyrin in which its radical shows four oxygen atoms, possibly due to the formation of the intramolecular hydrogen that consistently increases its polarity and activity in comparison with (1) $\alpha / \beta$-amyrin. Such feature may also suggest the high cytotoxicity of (2) 3- $O$-fumaryl- $\alpha / \beta$-amyrin. The low presence of oxygen atoms in the substituent groups at C-3 may also explain the lower activity of (1) $\alpha / \beta$-amyrin, (6) 3-O-acetyl-11-oxo$\alpha / \beta$-amyrin and (9) lup-20(29)-en-3-one.

Previous researches reported that the presence of hydroxyl group at C-3 and carboxyl group at C-17 is important for the parasitic activity. ${ }^{47}$ For this reason, (11) betulinic acid was more effective than (9) lup-20(29)-en-3-one. The lowest cytotoxicity of (9) lup-20(29)-en-3-one and the lowest antiamastigote activity of (7) 3-O-succinyl11 -oxo- $\alpha / \beta$-amyrin may be explained by oxidizing the $\mathrm{C}-3$ position and $\mathrm{R}_{2}$ position. Furthermore, the increase of the 
polarity of the compounds, nature and orientation of the substituents at C-3 and C-17 position may affect the activity of the triterpenes, mainly at $\mathrm{C}-3$ position in the majority compounds of this study. Indeed, the positions C-3 and C-17 are considered a target of chemical derivatization for the insertion of the different substituents. ${ }^{47}$ In addition, the presence of hydroxyl groups in different positions at C-3, C-6 and C-15 of (10) lup-20(29)-ene-3 $\beta, 6 \beta, 15 \beta$-triol as well as spatial configuration and several other factors may have influenced to the greater antiamastigote and cytotoxic activity.

The ultrastructural alterations, visualized by TEM of the $T$. cruzi intracellular parasites, revealed changes in the parasite shape, as well as ultrastructural alterations in the mitochondrion-kinetoplast complex and multiple cytoplasmic vacuolization. No changes were observed in the cell membrane permeability with the flow cytometry. These results can be associated with the absence of the rupture plasma membrane not seen by TEM. The plasma membrane rupture is modulated in response to the programmed cell death by necrosis, which is also characterized by the subsequent loss of the intracellular content and an increase in cell volume, ${ }^{19,48}$ thereby the present data exclude cell death by necrosis. Furthermore, amastigotes did not undergo any modification of the cell volume in the present study.

Except for combination of (1) $\alpha / \beta$-amyrin with (6) 3- $O$-acetyl-11-oxo- $\alpha / \beta$-amyrin at $\mathrm{IC}_{50}$ concentration, the flow cytometry analyses of triterpenoid-treated parasites showed a loss of the $\Delta \Psi \mathrm{m}$ with a decrease in Rh123 fluorescence intensity, resulting in mitochondrial depolarizing effects, mainly the treatment with $\mathrm{IC}_{90}$. The most pronounced depolarization found was obtained with the $\mathrm{IC}_{90}$ dosage with the combination between compounds (1) $\alpha / \beta$-amyrin with (6) 3-O-acetyl-11-oxo- $\alpha / \beta$-amyrin. In contrast, $\mathrm{IC}_{50}$ dosage of the combination between (1) $\alpha / \beta$-amyrin with (6) 3- $O$-acetyl-11-oxo- $\alpha / \beta$-amyrin displayed a mitochondrial membrane hyperpolarization that enhanced the total Rh123 fluorescence intensity. Part of these results may be correlated with ultrastructural mitochondrial alterations confirmed by TEM analyses, resulting in mitochondrial dysfunctions. The depolarization indicated an enhancement in the proton permeability through the inner mitochondrial membrane, the inhibition of the electron transport, or decrease in mitochondrial substrate transport/oxidation, which would impair proton pumping efflux and adenosine triphosphate synthesis, resulting in the parasite cell death. Specific mechanisms may be involved in the hyperpolarizing phenomena of the $\Delta \Psi \mathrm{m}$, such as complex II respiratory chain inhibition in the protozoan. ${ }^{49}$
The remarkable ultrastructural alterations seen by TEM were the formation of autophagosomes and autophagosome-like structures, such as dilated endoplasmic reticulum profiles and Golgi complex alterations, which surround cytoplasmic structures, and the formation of concentric myelin-like figures. These features are morphologically characterized as signs of the hallmark cell death of autophagy, in which their cellular components, such as the cytoplasm, organelles and protein aggregates, are catabolized for recycling as a pro-survival protection mechanism..$^{50}$ Not all the triterpenes induced the formation of autophagosome-like structures, which may suggest an autophagic process [(9) lup-20(29)-en-3-one]. For this reason, cell death by apoptosis can also be involved. Izumi et al. ${ }^{12}$ reported that some terpenes found in copaiba oils promoted parasite death by different mechanisms, including oxidative stress and autophagy. Thus, other studies should be carried out to further investigate the possible mechanisms involved in the cell death.

\section{Conclusions}

This study showed that triterpenes are promising compounds due to their excellent antiamastigote activities. Most compounds exhibited a low toxicity to the mammalian cells. The SAR of the triterpenes suggested that the insertion of more numbers of polar substituent groups may lead to greater selective compounds to the protozoan, thereby chemical derivatization can optimize the search of biological promising compounds with low toxicity to the host. Our results reinforce the importance of evaluating compounds with synergistic effects against the parasite and antagonistic effects against $\mathrm{LLCMK}_{2}$ cells, being an important alternative to treat the chronic stage of disease. Finally, the main cell death mechanism induced by triterpenoids against amastigotes suggests autophagy.

\section{Acknowledgments}

The authors thank to FAPERJ, FAPEAM, CNPq and CAPES.

\section{References}

1. Rassi Jr., A.; Rassi, A.; Marin-Neto, J. A.; Lancet 2010, 375, 1388.

2. Buckner, F. S.; Urbina, J. A.; Int. J. Parasitol. 2012, 2, 236.

3. Urbina, J. A.; Campo, R.; Trends Parasitol. 2003, 19, 495.

4. Chatelain, E.; Konar, N.; Drug Des. Dev. Ther. 2015, 9, 407.

5. Chatelain, E.; J. Biomol. Screening 2015, 20, 22. 
6. Ulla, A.; Baratto, L. C.; Paula, R. C.; Silva, L. H. V.; Soares, M. J.; Oliveira, B. H.; J. Braz. Chem. Soc. 2016, 27, 1245.

7. Silva Júnior, E. N.; Jardim, G. A. M.; Menna-Barreto, R. F. S.; Castro, S. L.; J. Braz. Chem. Soc. 2014, 25, 1780.

8. Thimmappa, R.; Geisler, K.; Louveau, T.; O’Maille, P.; Osbourn, A.; Annu. Rev. Plant Biol. 2016, 65, 225.

9. Mazumder, K.; Tanaka, K.; Fukase, K.; Molecules 2013, 18 , 8929.

10. Laszczyk, M. N.; Planta Med. 2009, 75, 1549.

11. Leite, A. C.; Ambrozin, A. R. P.; Fernandes, J. B.; Vieira, P. C.; Silva, M. F. G. F.; Albuquerque, S.; Planta Med. 2008, 74, 1795.

12. Izumi, E.; Ueda-Nakamura, T.; Veiga-Junior, V. F.; Pinto, A. C.; Nakamura, C. V.; J. Med. Chem. 2012, 12, 2994.

13. Ramírez-Macías, I.; Marín, C.; Chahboun, R.; Messouri, I.; Olmo, F.; Rosales, M. J.; Gutierrez-Sánchez, R.; Alvarez-Manzaneda, E.; Sánchez-Moreno, M.; Am. Soc. Trop. Med. Hyg. 2012, 87, 481.

14. Santos, A. O.; Ueda-Nakamura, T.; Dias Filho, B. P.; Veiga-Junior, V. F.; Nakamura, C. V.; Evid. Based Complement. Alternat. Med. 2012, DOI: 10.1155/2012/898419.

15. Santos, A. O.; Izumi, E.; Ueda-Nakamura, T.; Dias-Filho, B. P.; Veiga-Junior, V. F.; Nakamura, C. V.; Mem. Inst. Oswaldo Cruz 2013, 108, 59.

16. Santos, V. A. F. F. M.; Leite, K. M.; Siqueira, C. M.; Regasini, L. O.; Martinez, I.; Nogueira, C. T.; Galuppo, M. K.; Stolf, B. S.; Pereira, A. M. S.; Cicarelli, R. M. B.; Furlan, M.; Graminha, M. A. S.; Molecules 2013, 18, 1053.

17. Izumi, E.; Ueda-Nakamura, T.; Veiga-Junior, V. F.; Nakamura, C. V.; Planta Med. 2013, 79, 952.

18. Castro, S. L.; Batista, D. G. J.; Batista, M. M.; Batista, W. D. A.; Souza, E. M.; Menna-Barreto, R. F. S.; Oliveira, G. M.; Salomão, K.; Silva, C. F.; Silva, P. B.; Nazar, M.; Soeiro, C.; Mol. Biol. Int. 2011, DOI: 10.4061/2011/306928.

19. Rodrigues, J. H. S.; Ueda-Nakamura, T.; Corrêa, A. G.; Sangi, D. P.; Nakamura, C. V.; PLoS One 2014, 9, 85706.

20. Martins, T. A. F.; Diniz, L. F.; Nascimento, A. F. S.; Caldas, S.; Caldas, I. V.; Andrade, I. M.; Ribeiro, I.; Bahia, M. T.; PLoS One 2015, 9, 4807.

21. Castro, J. A.; De Mecca, M. M.; Bartel, L. C.; Hum. Exp. Toxicol. 2006, 25, 471.

22. Sonar, V. P.; Corona, A.; Distinto, S.; Maccioni, E.; Meleddu, R.; Fois, B.; Floris, C.; Malpure, N. V.; Alcaro, S.; Tramontano, E.; Cottiglia, F.; Eur. J. Med. Chem. 2017, 130, 248.

23. Silva Júnior, W.; Pinheiro, J.; Moreira, C.; Rüdiger, A.; Barbosa, E.; Lima, E.; Veiga Júnior, V. F.; Silva Júnior, A.; Aragão, C.; Lima, A.; J. Therm. Anal. Calorim. 2017, 127, 1757.

24. de Almeida, P. D. O.; Boleti, A. P. A.; Rüdiger, A. L.; Lourenço, G. A.; Veiga Junior, V. F.; Lima, E. S.; Yasukawa, K.; Evid. Based Complement. Alternat. Med. 2015, 2015, 10.

25. Rüdiger, A. L.; Veiga-Junior, V. F.; Chem. Biodiversity 2013, 10,1142 .
26. Dias, M. O.; Hamerski, L.; Pinto, A. C.; Quim. Nova 2011, 34, 704.

27. Barros, F. W.; Bandeira, P. N.; Lima, D. J.; Meira, A. S.; de Farias, S. S.; Albuquerque, M. R.; dos Santos, H. S.; Lemos, T. L.; de Morais, M. O.; Costa-Lotufo, L. V. Pessoa, C. O.; Bioorg. Med. Chem. 2011, 19, 1268.

28. Okoye, N. N.; Ajaghaku, D. L.; Okeke, H. N.; Ilodigue, E. E.; Nworu, C. S.; Okoye, F. B.; Pharm. Biol. 2014, 52, 1478.

29. Agrawal, P. K.; Jain, D. C.; Prog. NMR Spectr. 1992, $24,1$.

30. Barnes, R. A.; Pereira, A. L.; Scofield, T. C. V.; Brás Filho, R.; Pinto, A. C.; Chem. Pharm. Bull. 1984, 32, 3674.

31. Facundo, V. A.; Andrade, C. H. S.; Silveira, E. R.; Braz-Filho, R.; Hufford, C. D.; Phytochemistry 1993, 32, 411.

32. Cota, B. B.; Siqueira, E. P.; Oliveira, D. M.; Alves, T. M. A.; Sobral, M. E. G.; Rabello, A.; Zani, C. L.; Braz. J. Pharmacog. 2012, 22, 1253.

33. Carpenter, R. S.; Sotheeswaran, S.; Sultanbawa, M. U. S.; Ternai, B.; Org. Magn. Reson. 2015, 14, 462.

34. Leão De Souza, A. D.; Souza, A. D. L.; Rocha, A. F. I.; Pinheiro, M. L. B.; Andrade, C. H. S.; Queiroz, A. L. A. G.; Santos, M. P. S. S.; Quim. Nova 2001, 24, 439.

35. Kavtaradze, L. K.; Manley-Harris, M.; Nicholson, B. K.; Steroids 2004, 69, 697.

36. Nana, F.; Sandjo, L. P.; Keumedjio, F.; Ambassa, P.; Malik, R.; Kuete, V.; Rincheval, V.; Choudhary, M. I.; Ngadjui, B. T.; J. Braz. Chem. Soc. 2012, 3, 482.

37. Mendes, C. C.; Sandes, L. Q.; Cruz, F. G.; Roque, N. F.; Chem. Biodiversity 2009, 6, 1463.

38. Brener, Z.; Rev. Inst. Med. Trop. São Paulo 1962, 4, 386.

39. Mosmann, T.; J. Immunol. Methods 1983, 16, 55.

40. Chou, T. C.; Talalay, P.; Adv. Enzyme Regul. 1984, 22, 27.

41. Urbina, J. A.; J. Euk. Microbiol. 2015, 62, 149.

42. Leon, J. S.; Engman, D. M.; Int. J. Parasitol. 2001, 31, 555.

43. Ferreira, D. S.; Esperandim, V. R.; Alonso, M. P.; Kuehn, T. C. C.; Júnior, J. C. P.; Cunha, W. R.; Silva, M. L. A.; Albuquerque, S.; Exp. Parasitol. 2013, 134, 455.

44. Lozano, E.; Barrera, P.; Romina, S.; Nieto, I. V.; Tonn, M. C.; Kemmerling, U.; Mortara, R. A.; Sosa, M. A.; Parasitol. Int. 2012, 61, 628 .

45. Lozano, E.; Barrera, P.; Tonn, C.; Nieto, M.; Sartor, T.; Sosa, M. A.; Parasitol. Int. 2012, 61, 275.

46. Xia, Q.; Zhang, H.; Sun, X.; Zhao, H.; Zhu, L. W. D.; Yang, G.; Shao, Y.; Zhang, X.; Mao, X.; Zhang, L.; She, G.; Molecules 2014, 19, 17478.

47. Isah, M. B.; Ibrahim, M. A.; Mohammed, A.; Aliyu, A. B.; Masola, B.; Coetzer, T. H. T.; Parasitol. 2015, 143, 1219; Leite, J. P.; Oliveira, A. B.; Lombardi, A. J.; Filho, J. D. S.; Chiari, E.; Biol. Pharm. Bull. 2006, 29, 2307; Ferreira, D. S.; Esperandim, V. R.; Toldo, M. P.; Saraiva, J.; Cunha, W. R.; Albuquerque, S.; Parasitol. Res. 2010, 106, 985. 
48. Menna-Barreto, R. F.; Salomão, K.; Dantas, A. P.; Santa-Rita, R. M.; Soares, M. J.; Barbosa, H. S.; Castro, S. L.; Micron 2009, 40, 157.

49. Tiuman, T. S.; Ueda-Nakamura, T.; Alonso, A.; Nakamura, C. V.; BMC Microbiol. 2014, 14, 152; Sen, N.; Das, B. B.; Ganguly, A.; Mukherjee, T.; Tripathi, G.; Bandyopadhyay, S.; Rakshit, S.; Sem, T.; Majumder, H. K.; Cell Death Differ. 2004, 11, 924; Mehta, A.; Shaha, C.; J. Biol. Chem. 2004, 279, 11798.

50. Chaabane, W.; User, S. D.; El-Gazzah, M.; Jaksik, R.; Sajjadi, E.; Rzeszowska-Wolny, J.; Los, M. J.; Arch. Immunol. Ther. Exp. 2013, 61, 43; Queiroz, K. C. S.; Milani, R.; Ruela-de-Sousa, R. R.; Fuhler, G. M.; Justo, G. Z.; Zambuzzi, W. F.; Duran, N.;
Diks, S. H.; Spek, C. A.; Carmen, V. F.; Peppelenbosch, M. P.; PLoS One 2012, 7, 4536; Schontal, A. A.; Scientifica 2012, DOI: 10.6064/2012/857516; Adade, M. A.; Oliveira, I. R. S.; Pais, J. A. R.; Souto-Padrón, T.; Toxicon 2013, 69, 227; Meira, C. S.; Guimarães, E. T.; Bastos, T. M.; Moreira, D. R.; Tomassini, T. C.; Ribeiro, I. M.; Santos, R. R.; Soares, M. B.; Parasitology 2013, 140, 1811; Veiga-Santos, P.; Reignault, L. C.; Huber, K.; Bracher, F.; De Souza, W.; De Carvalho, T. M.; Parasitology 2014, 141, 814 .

Submitted: March 20, 2017

Published online: June 6, 2017 